\author{
Medizinische Fakultät \\ der \\ Universität Duisburg-Essen
}

Aus der Klinik für Neurochirurgie und Wirbelsäulenchirurgie

\title{
Intracranial aneurysms in patients with tuberous sclerosis complex: a systematic review
}

\author{
In a g u ra $1-D$ is sertation \\ zur
}

Erlangung des Doktorgrades der Medizin

Durch die Medizinische Fakultät

der Universität Duisburg-Essen

Vorgelegt von

Mehdi Chihi

aus Tunis, Tunesien

Essen 2019 
DuEPublico

Duisburg-Essen Publications online

\section{$D_{E} U_{S} I_{S} S^{B} B_{N}$ U R G}

offen im Denken

Diese Dissertation wird über DuEPublico, dem Dokumenten- und Publikationsserver der Universität Duisburg-Essen, zur Verfügung gestellt und liegt auch als Print-Version vor.

DOI: $\quad 10.17185 /$ duepublico/70798

URN: urn:nbn:de:hbz:464-20200610-111753-8

Vorsitzende:

1.Gutachter:

2.Gutachter:
Herr Univ-Prof. Dr. med. J. Buer

Herr Priv.-Doz. Dr. med. K. H. Wrede

Herr Prof. Dr. med. A. Radbruch

Tag der mündlichen Prüfung: 17. September 2019 


\section{Table of Contents:}

Intracranial aneurysms in patients with tuberous sclerosis complex: a systematic review.

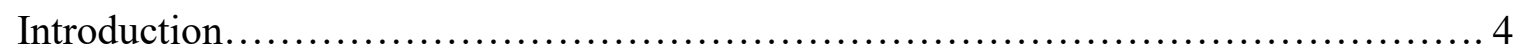

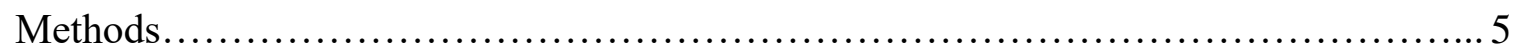

-Data Sources............................................................... 5

-Data Collection............................................................ 5

-Outcomes.............................................................. 5

-Statistical Analysis................................................. 5

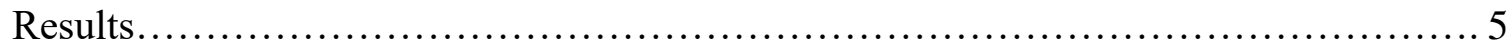

-Case Reports....................................................5

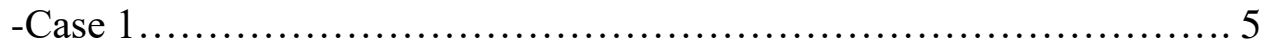

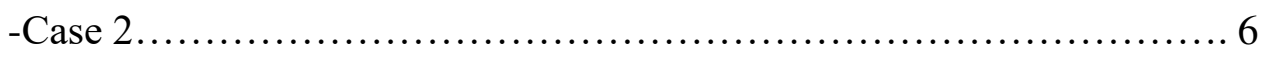

-Literature Review...................................................6 6

-Demographic Data and Clinical Characteristics......................... 6

-Characteristics of the Aneurysms: Location and Hemorrhagic Presentation.......6

-Diagnostic and Treatment Modalities..................................... 7

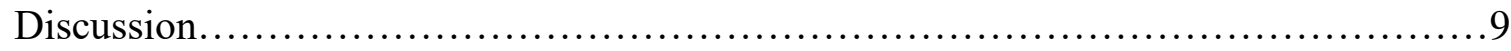

-Characteristics of IAs in TSC Patients................................... 9

-Pathogenesis of IA Development in TSC ...................................11

-Recommendations............................................... 11

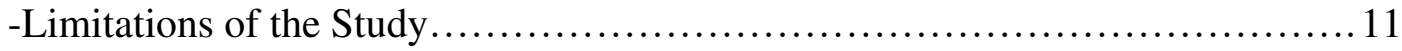

Conclusions............................................................. 12

References............................................................. 12

Vasospasm-related complications after subarachnoid hemorrhage: the role of patient's age and sex.

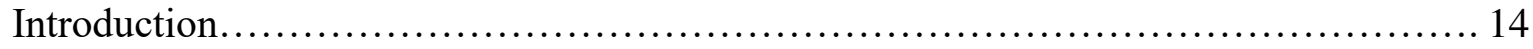

Material and Methods...................................................... 15 
-Data Management and Statistics........................................... 15

Results.................................................................. 15

-Predictors of SV, DCI, and outcome.................................... 16

-Differences between males and females: baseline parameters...................16

-Association between age and sex for SV risk............................. 16

-The role of sex-specific age groups for DCI risk.......................... 16

-The role of sex-specific age groups for functional outcome................... 16

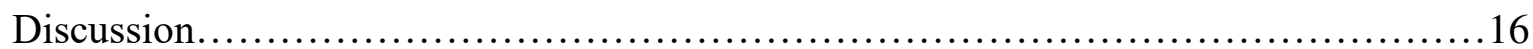

-SV and DCI after SAH: common predictors.............................. 16

-Different age patterns for vasospasm risk in males and females................ 17

-Limitations......................................................... 18

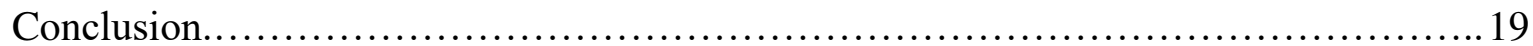

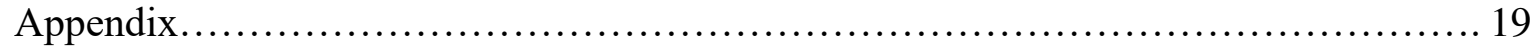

References..................................................................... 20

Acknowledgment................................................................. 22

Curriculum vitae.............................................................. 23 


\title{
Intracranial aneurysms in patients with tuberous sclerosis complex: a systematic review
}

\author{
Mehdi Chihi, MD, Oliver Gembruch, MD, Marvin Darkwah Oppong, MD, Bixia Chen, MD, \\ Thiemo Florin Dinger, MD, Lennart Barthel, MD, Daniela Pierscianek, MD, Karsten H. Wrede, MD, \\ Neriman Özkan, MD, Ulrich Sure, MD, and Ramazan Jabbarli, MD \\ Department of Neurosurgery, University Hospital Essen, University of Duisburg-Essen, Essen, Germany
}

\begin{abstract}
OBJECTIVE Tuberous sclerosis complex (TSC) is a rare multisystem genetic disease. Arterial wall developmental disorders, such as aneurysms, in association with TSC have been well described for extracranial vasculature. The characteristics of intracranial aneurysms (IAs) in TSC have not previously been addressed in the literature. This systematic review was performed to identify and assess the distinct characteristics of IAs in patients with TSC.
\end{abstract}

METHODS The authors searched PubMed, Scopus, and Web of Science for publications describing cases of TSC and IA reported before August 7, 2018. They also report 2 cases of IAs in TSC patients treated at their own institution.

RESULTS Thirty-three TSC patients with a total of 42 IAs were included in this review. Three individuals presented with subarachnoid hemorrhage. The IAs were large or giant in $57.1 \%$ and fusiform in $45.2 \%$ of the cases. Most of the IAs $(61.9 \%, 26$ of 42$)$ originated from the internal carotid artery. There was a higher prevalence of pediatric cases $(66.7 \%)$ and male patients $(63.6 \%, 21$ of 32 individuals with known sex) among the collected series.

CONCLUSIONS TSC patients with IAs are characterized with a higher proportion of large/giant and fusiform IAs and young age, suggesting rapid aneurysmal growth. Furthermore, there is a distinct location pattern of IAs and an inverse sex ratio than in the healthy population. Large population-based patient registers are required to improve the understanding of epidemiology and pathophysiology of IA formation in TSC.

https://thejns.org/doi/abs/10.3171/2019.2.PEDS18661

KEYWORDS tuberous sclerosis; intracranial aneurysm; fusiform aneurysm; subarachnoid hemorrhage; vascular disorders

$\mathrm{T}$ UBEROUS sclerosis complex (TSC) belongs to the group of phakomatoses. It is a genetic disorder with an autosomal dominant inheritance, which can affect virtually any organ in the body. The most common findings are benign tumors of the brain, skin, kidney, lungs, bone, and heart. ${ }^{30}$ Its clinical manifestation was first described by Vogt as a combination of 3 symptoms: epilepsy, mental retardation, and adenoma sebaceum. ${ }^{14} \mathrm{How}-$ ever, this triad is only present in $29 \%$ of cases; seizures are absent in $25 \%$ of cases, and intellectual disability is not present in $45 \%$ of cases. ${ }^{14}$ TSC was underdiagnosed until the 1980s, when individuals with less severe manifesta- tions began to be recognized. ${ }^{30}$ It has an incidence of 1 per 30,000 in the general population and a birth incidence of 1 per 5800.32 Arterial wall anomalies, such as kidney aneurysms, were described in TSC and were considered the result of developmental defects. ${ }^{5}$

Intracranial aneurysms (IAs) in patients with TSC are extremely rare. The first case was described by Snowdon in 1974, reporting the coexistence of an aneurysm of the right middle cerebral artery (MCA) in a patient with TSC, who died after subarachnoid hemorrhage (SAH) due to aneurysm rupture. ${ }^{36}$ Because of the small number of patients and the lack of large and uniform studies, the natural

ABBREVIATIONS $A C A=$ anterior cerebral artery; $A C O A=$ anterior communicating artery; $A D P K D=$ autosomal dominant polycystic kidney disease; $A S A=$ acetylsalicylic acid; $D S A=$ digital subtraction angiography; $I A=$ intracranial aneurysm; ICA = internal carotid artery; $M C A=$ middle cerebral artery; $M R A=$ magnetic resonance angiography; $\mathrm{MRI}=$ magnetic resonance imaging; $\mathrm{PCA}=$ posterior cerebral artery; $\mathrm{PCOA}=$ posterior communicating artery; PRISMA = Preferred Reporting Items for Systematic Reviews and Meta-Analyses; $\mathrm{SAH}=$ subarachnoid hemorrhage; $\mathrm{STA}=$ superficial temporal artery; $\mathrm{TOF}=$ time-of-flight; $\mathrm{TSC}=$ tuberous sclerosis complex; UIA = unruptured intracranial aneurysm.

SUBMITTED October 30, 2018. ACCEPTED February 22, 2019.

INCLUDE WHEN CITING Published online May 10, 2019; DOI: 10.3171/2019.2.PEDS18661. 
TABLE 1. Search syntax

\begin{tabular}{|c|c|c|}
\hline PubMed Search (143 articles) & Scopus Search (242 articles) & Web of Science Search (184 articles) \\
\hline $\begin{array}{l}\text { ((tuberous sclerosis) OR (tuberous } \\
\text { sclerosis complex) OR (contiguous } \\
\text { gene syndrome)) AND ((aneurysm) OR } \\
\text { (intracranial aneurysm) OR (subarach- } \\
\text { noid hemorrhage) OR (clipping) OR } \\
\text { (endovascular treatment) OR (coiling) OR } \\
\text { (occlusion)) }\end{array}$ & $\begin{array}{l}\text { (TITLE-ABS-KEY ("tuberous sclerosis" } \\
\text { OR "tuberous sclerosis complex" OR } \\
\text { "contiguous gene syndrome") AND } \\
\text { TITLE-ABS-KEY ("aneurysm" OR } \\
\text { "intracranial aneurysm" OR "subarach- } \\
\text { noid hemorrhage" OR "clipping" OR } \\
\text { "endovascular treatment" OR "coiling" } \\
\text { OR "occlusion")) }\end{array}$ & $\begin{array}{l}\text { TOPIC: (tuberous sclerosis OR tuberous } \\
\text { sclerosis complex OR contiguous gene } \\
\text { syndrome) AND TOPIC: (aneurysm OR } \\
\text { intracranial aneurysm OR subarachnoid } \\
\text { hemorrhage OR clipping OR endovascu- } \\
\text { lar treatment OR coiling OR occlusion) }\end{array}$ \\
\hline
\end{tabular}

* All searches were performed on August 7, 2018.

history and characteristics of IAs in TSC patients remain unclear. In order to improve the understanding of IAs in these patients, we performed a systematic review of all the published case reports and studies describing IAs in TSC, as well as included 2 cases from our institution.

\section{Methods \\ Data Sources}

A comprehensive literature search of 3 databases (PubMed, Scopus and Web of Science) was performed by the first author (M.C.) in accordance with the PRISMA (Preferred Reporting Items for Systematic Reviews and Meta-Analyses) guidelines. ${ }^{28}$ The search strategy is reported in Table 1. The keywords "tuberous sclerosis," "tuberous sclerosis complex," "contiguous gene syndrome," "aneurysm," "intracranial aneurysm," "subarachnoid hemorrhage," "clipping," "endovascular treatment," "coiling," and "occlusion" were used in both "AND" and "OR" combinations. The search was limited to articles published from 1900 to August 2018 in the English language. All studies reporting cases or series of TSC patients with diagnosis of IA based on vascular imaging (digital subtraction angiography [DSA], magnetic resonance imaging [MRI] and MR angiography [MRA], or CT angiography) and/or autopsy were eligible for the review.

In addition, we screened our observational database containing records of all consecutive patients with IAs treated at our institution since 2003. This observational study has been approved by the local Institutional Ethics Committee (Ethik-Kommission, Medizinische Fakultät der Universität Duisburg-Essen). The study was registered in the German clinical trial register (Deutsches Register klinischer Studien [DRKS]). Screening of our observational database yielded 2 additional cases of IA associated with TSC, and these cases were included in our analysis. In both cases, patient informed consent was obtained.

\section{Data Collection}

From each study, the following information was extracted: 1) demographic characteristics, 2) circumstances of diagnosis, 3) presence of a TSC2/PKDI contiguous gene syndrome, 4) presence of autosomal dominant polycystic kidney disease (ADPKD), 5) number, status, location, size, and form of the IAs, 6) diagnostic and treatment modalities, 7) success of treatment, and 8) neurological outcome. IAs from internal carotid arteries (ICAs) included aneu- rysms arising from the posterior communicating artery (PCoA) and the cavernous segment. Aneurysm size was categorized into 3 groups based on maximum diameter: small $(<10 \mathrm{~mm})$, large $(10-24 \mathrm{~mm})$, and giant $(\geq 25 \mathrm{~mm})$.

\section{Outcomes}

The primary objectives of this study were: 1) to review all publications describing cases of IAs in TSC patients, and 2) to determine the characteristics of the IAs associated with TSC. The secondary objectives were to examine the diagnostic and the treatment modalities of the aneurysms and the treatment-related outcomes, including: 1) proportion of patients treated with clipping, coiling, or vessel occlusion, and 2) complications and neurological outcome after treatment. Treatment success was defined as complete or near-complete occlusion of the aneurysm. In cases in which the occlusion grade was not reported, treatment was considered successful if the authors described the outcome with phrases such as "thrombosis of the aneurysm" or "absence of flow signal intensity into the aneurysm lumen" or "aneurysm excluded from the circulation."

\section{Statistical Analysis}

All analyses were performed using IBM SPSS Statistics version 25 for Windows. Continuous values are expressed as means (with ranges and/or standard deviations). Categorical data are presented as frequencies and percentages. Based on the 1-sample t-test, we calculated $95 \%$ confidence intervals for the incidence. Due to a lack of accurate and completed numerical information, we mainly conducted descriptive analysis.

\section{Results \\ Case Reports}

Case 1

A 14-month-old boy suffering from TSC and a growing IA presented to our neurosurgical department. At the age of 2.5 months, he had presented with new-onset focal seizures. Thus, an MRI was performed and a left cavernous ICA aneurysm (8 $\mathrm{mm}$ in diameter) was identified. MRI follow-up revealed a rapid growth of the IA within 5 months, reaching a diameter of $13.8 \mathrm{~mm}$ (Fig. 1). When the patient was 14 months old, digital subtraction angiography (DSA) was performed, revealing an aneurysm diameter of $18.8 \mathrm{~mm}$. Consequently, the IA was treated by emboliza- 


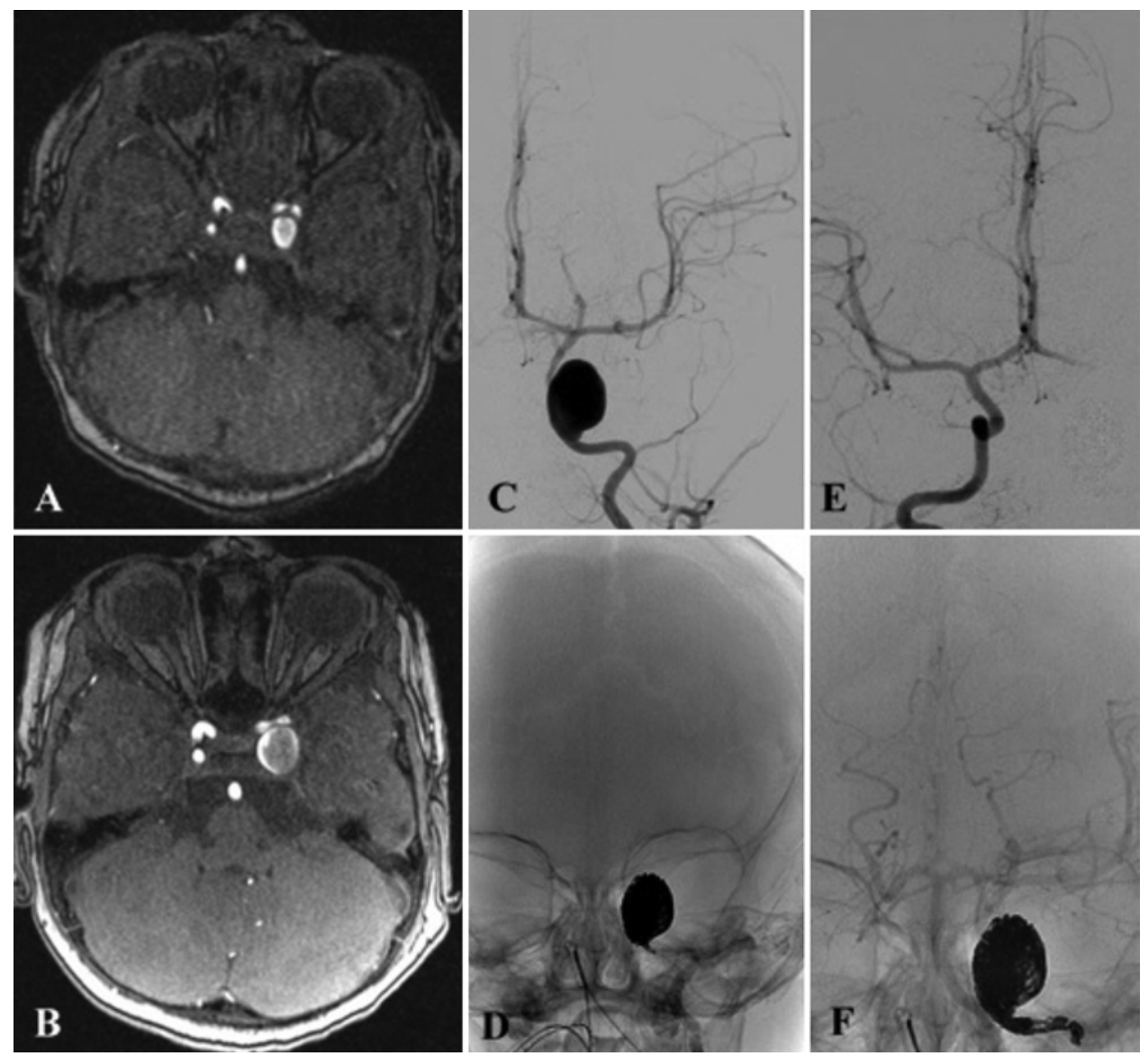

FIG. 1. Case 1. A and B: TOF-MRA images obtained at initial presentation (A), showing an 8-mm-diameter left cavernous ICA aneurysm, and 5 months later, showing rapid growth (B, diameter $13.8 \mathrm{~mm}$ ). C: DSA image obtained when the patient was 14 months old showing an aneurysm diameter of $18.8 \mathrm{~mm}$. D: DSA image obtained immediately after treatment (coil embolization of the aneurysm and parent vessel occlusion). E and F: DSA images showing that the left hemisphere was still perfused by collateral blood flow from the right ICA through the ACOA (E) and from the left PCA through the left PCoA (F).

tion and parent vessel occlusion. No neurological deficits were noticed after treatment and the child tolerated the total occlusion of the left ICA.

\section{Case 2}

A 20-year-old woman with a prior diagnosis of TSC presented to our neurosurgical department with an incidental aneurysm of the right ICA (Fig. 2). DSA showed a 9-mm-diameter saccular ICA aneurysm, and the lesion was successfully clipped. The patient had no neurological deficits after surgery.

\section{Literature Review}

Of 569 publications identified during the search, 28 articles were included in this review. The characteristics of 31 patients collected from these case reports are summarized in Table 2. The search flow diagram is shown in Fig. 3.

\section{Demographic Data and Clinical Characteristics}

Including the 2 new cases that we report here, a total of 33 patients with 42 aneurysms were included in this study. ${ }^{1-3,5-8,10-12,15-18,20,21,23,25,26,31,33-40}$ Twenty-one patients were male, 11 were female, and in 1 case, the patient's sex was not mentioned. The male/female ratio was 1.9:1. The age of the patients, at the time of aneurysm diagnosis, varied from 2.5 months to 53 years (mean age [ $\pm \mathrm{SD}] 15.4$ \pm 2.5 years, $95 \%$ CI $10.3-20.5$ years). Among the 33 patients, we counted $22(66.7 \%)$ pediatric patients (age $\leq 18$ years) with unruptured intracranial aneurysms (UIAs). ${ }^{1,3}$, 5-8,11,12,17,18,20,21,23,33,35,37-40 Eight patients were 2 years of age or younger and 13 patients were between 6 and 17 years of age. In 1 case (involving an infant), the patient's age was not mentioned. The mean age of patients with TSC and UIAs was lower than that of the subgroup with ruptured aneurysms $(12.7 \pm 2.4$ vs $33.3 \pm 4.6$ years). In 2 cases $(1$ pediatric and 1 adult), ADPKD was diagnosed. In 3 cases (1 pediatric and 2 adult), a TSC2/PKDI contiguous syndrome was diagnosed.

\section{Characteristics of the Aneurysms: Location and Hemorrhagic Presentation}

The characteristics of the IAs are summarized in Table 2. In 3 cases, the IAs were ruptured (7.1\%) and in another case (2.4\%), aneurysm rupture was probable, because the patient had had severe headaches at the time of consulta- 

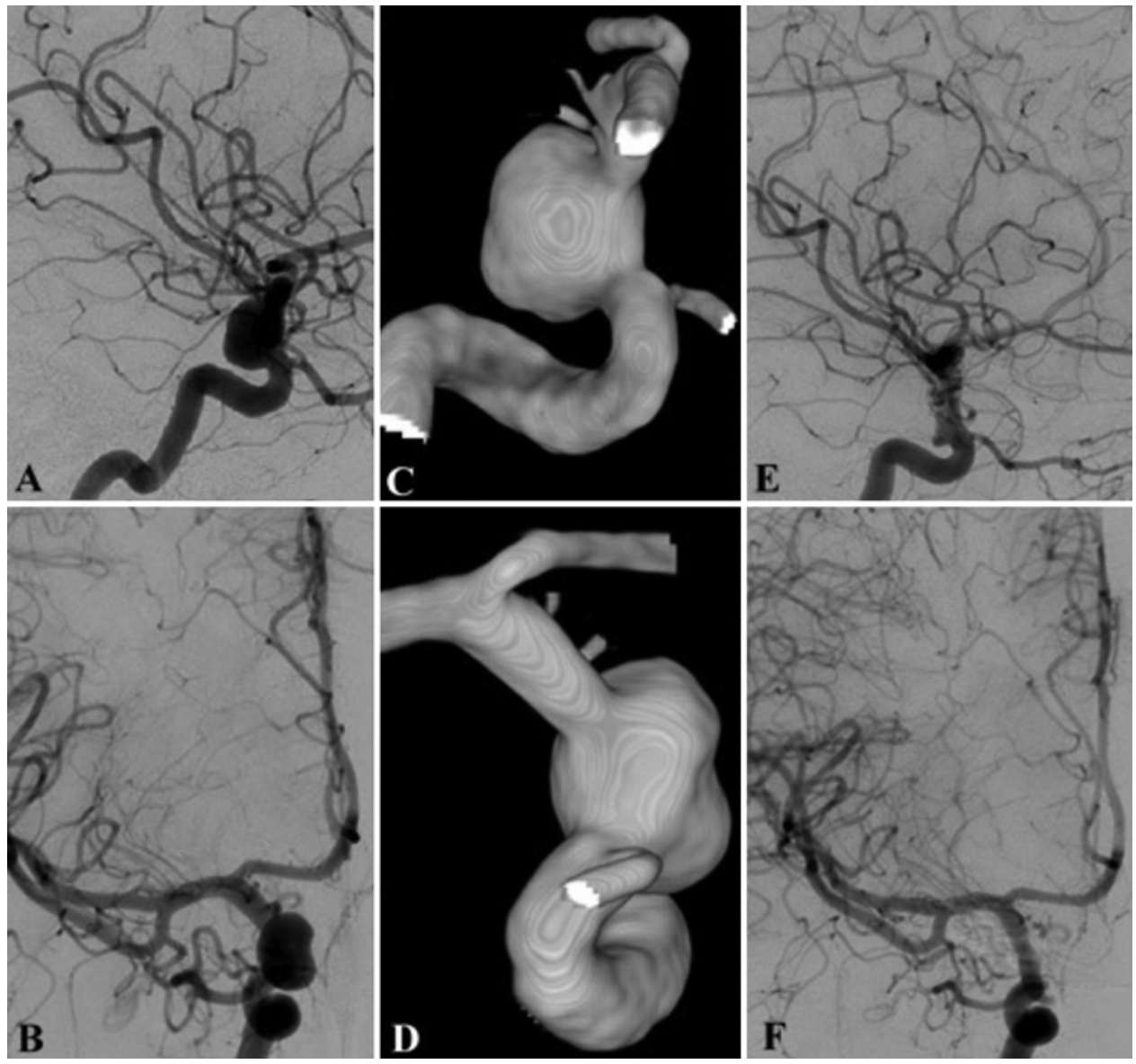

FIG. 2. Case 2. A and B: DSA images showing an anterior (A) and a lateral $(B)$ view of the incidental 9-mm-diameter saccular aneurysm of the right ICA. C and D: 3D reconstructions of both views. Clipping was successfully performed. E and F: Postoperative DSA images showing occlusion of the intradural portion of the aneurysm, with a small extradural aneurysm remnant.

tion. However, rupture status was not reported in this latter case. The mean number of IAs per patient was 1.27. Of the 42 IAs, 36 were in the anterior circulation $(85.7 \%)$ and the other 6 were in the vertebrobasilar system. Most of the IAs originated from the ICA $(61.9 \%, \mathrm{n}=26)$ or the anterior cerebral artery/anterior communicating artery (ACA/ $\mathrm{ACoA})(14.3 \%, \mathrm{n}=6)$. Occasionally, aneurysms originated from the vertebrobasilar complex $(11.9 \%, \mathrm{n}=5)$, the MCA $(7.1 \%, \mathrm{n}=3)$, the posterior cerebral artery (PCA) $(2.4 \%$, $\mathrm{n}=1$ ), or from the glomus choroideum of the right lateral ventricle $(2.4 \%, \mathrm{n}=1)$. Multiple IAs were found in $7(21.2 \%)$ of 33 patients (6 pediatric patients and 1 young woman with SAH). Of the 42 IAs reported, 7 (16.7\%) were small, $14(33.3 \%)$ were large, and $10(23.8 \%)$ were giant. The size of the other 11 IAs was not mentioned. Nineteen (45.2\%) of the 42 IAs were fusiform and $9(21.4 \%)$ were saccular. The form of the other 14 IAs was not mentioned. Thirteen IAs were large/giant and fusiform; 7 were small and/or saccular; and 22 were reported without mentioning the form and/or the size. All patients with large/giant and fusiform aneurysms ( $\mathrm{n}=10,13$ IAs) were pediatric, with a male predominance (6 males, 3 females, 1 unknown sex), and most of the IAs were in the anterior circulation (ICA) $(70 \%, \mathrm{n}=7)$.

\section{Diagnostic and Treatment Modalities}

Data regarding diagnostic and treatment modalities as well as neurological outcome after treatment are summarized in Table 3. IAs were diagnosed incidentally in 12 cases (36.4\%), due to a new onset of a neurological deficit in 7 cases $(21.2 \%)$, based on clinical manifestations of acute SAH in 2 cases (6.1\%), due to incomplete seizure control in 2 cases (6.1\%), at autopsy in 2 cases (6.1\%) (in 1 patient the aneurysm was ruptured and caused $\mathrm{SAH}$ ), and as a result of a workup for a severe headache in 1 case (3\%). In 7 cases $(21.2 \%)$, the circumstances of diagnosis were not mentioned. The most common diagnostic modality was DSA $(57.6 \%, \mathrm{n}=19)$, followed by MRI $(30.3 \%, \mathrm{n}$ $=10)$; autopsy $(6.1 \%, \mathrm{n}=2)$ was the least common method of diagnosis. The diagnostic modality was not mentioned in 2 cases.

Seventeen IAs (including 2 ruptured IAs) were treated in 16 patients. Microsurgical treatment was the most common approach and included 8 clipping procedures and 1 surgical ICA occlusion after superficial temporal artery (STA)-MCA bypass $(52.9 \%, \mathrm{n}=9)$. Endovascular treatment was performed in 8 cases (47.1\%) and included 2 ICA occlusions and 6 coiling procedures; of the 6 coiling procedures, two were stent-assisted, and one of the 


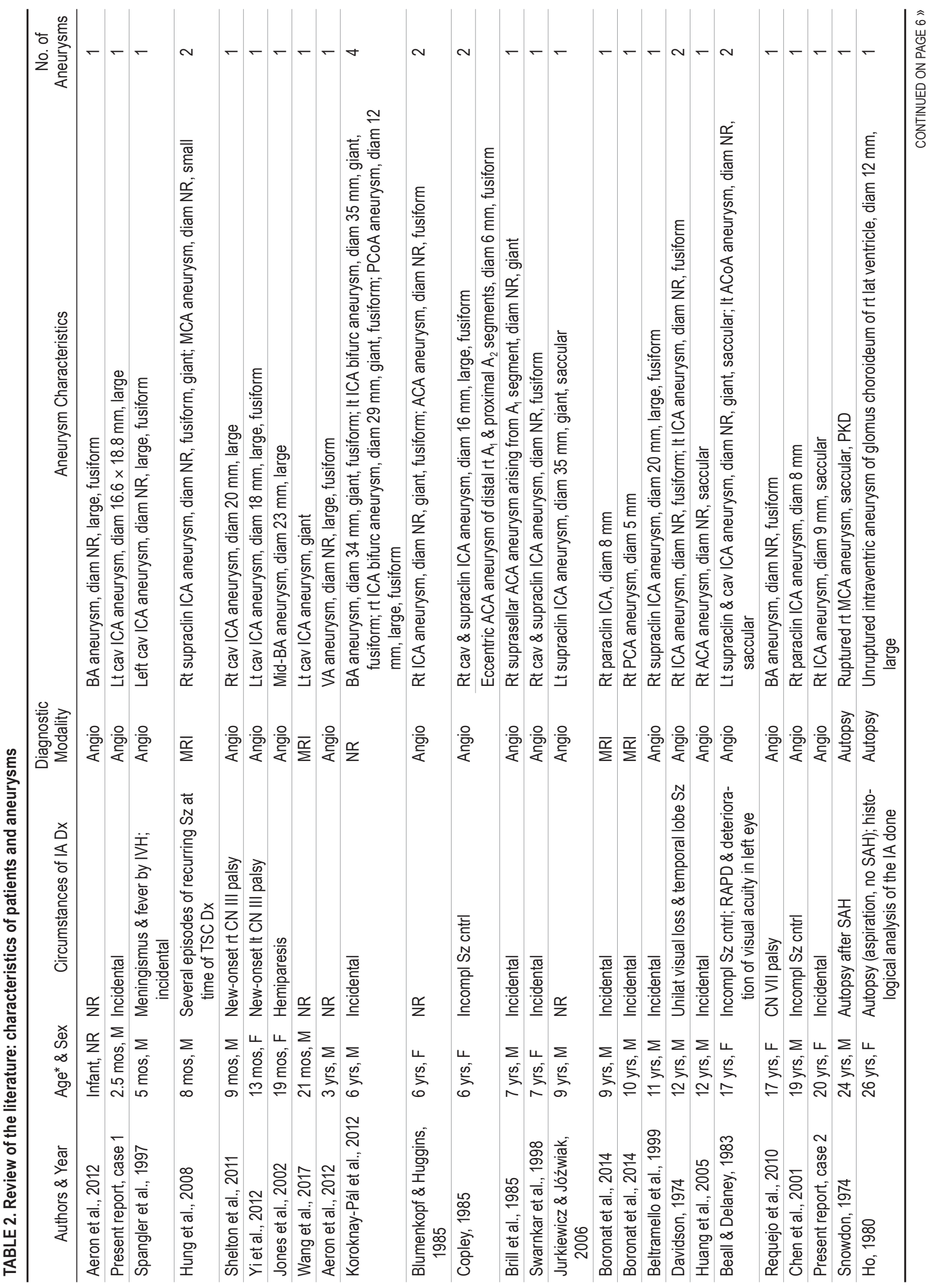




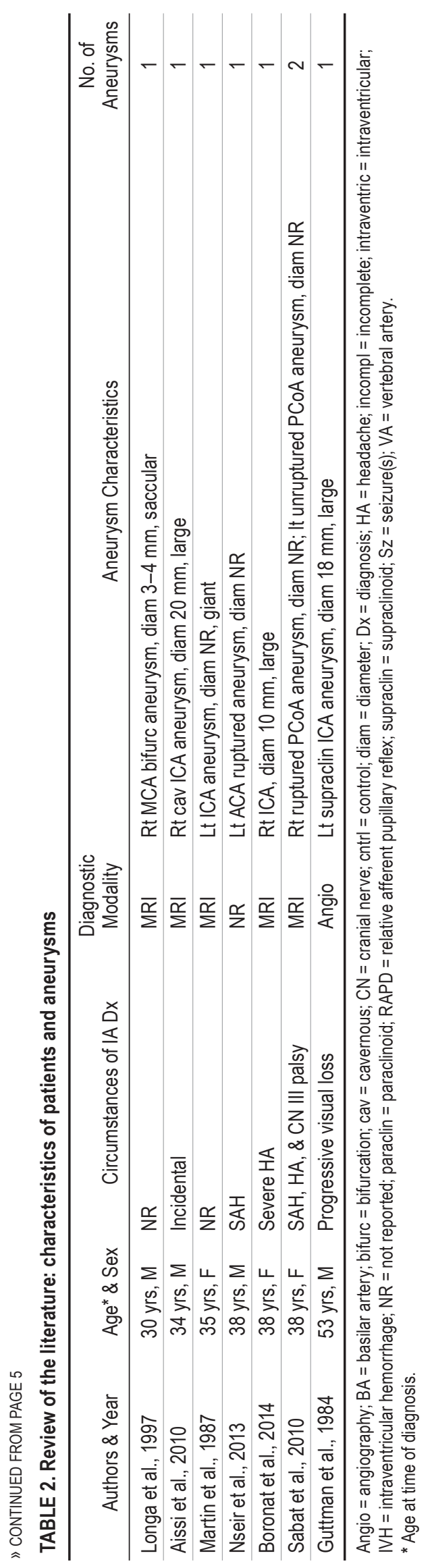

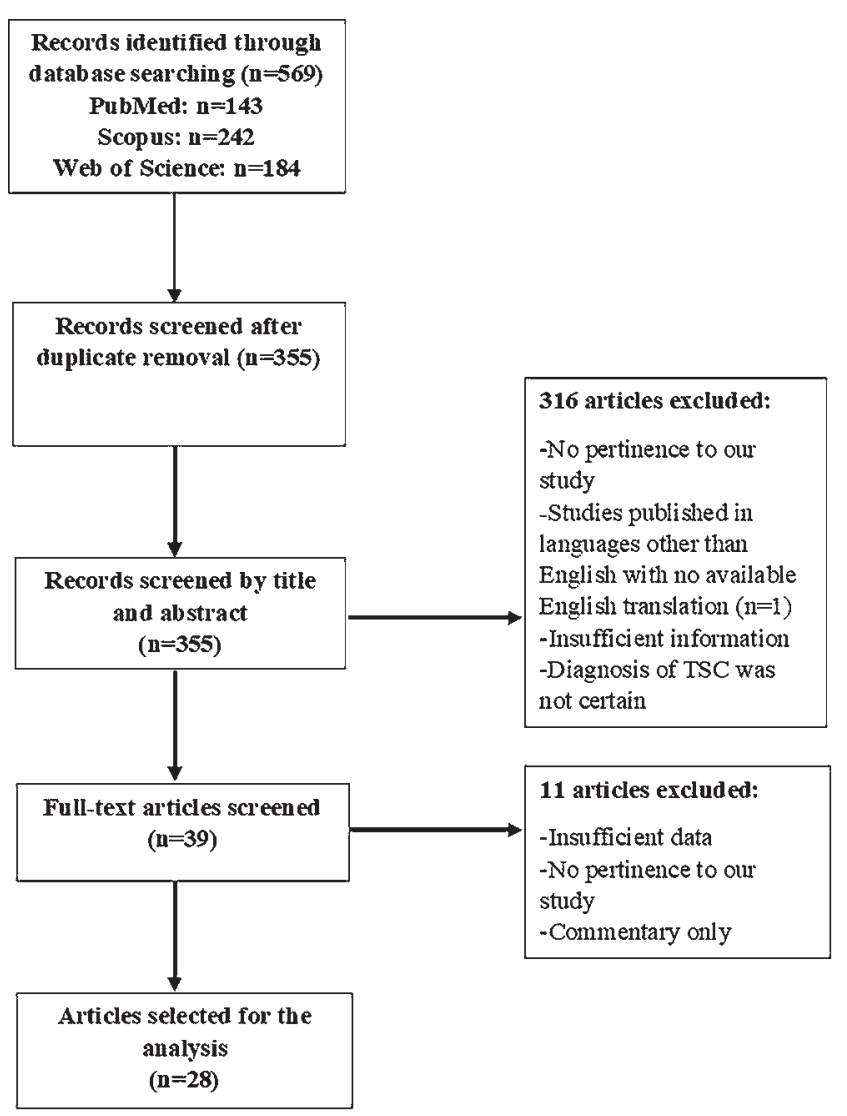

FIG. 3. PRISMA diagram detailing the specifics of the systematic literature review.

other four was followed by an ICA occlusion. There was an increase in endovascular treatment in cases reported in the last 2 decades ( 8 of 13 IAs, $61.5 \%$ ), presumably due to advances in neurovascular techniques. One patient with an asymptomatic partially thrombosed IA of the right cavernous ICA was treated conservatively with $250 \mathrm{mg}$ acetylsalicylic acid (ASA) daily. The authors provided no information on the further clinical course of this patient under ASA treatment.

\section{Discussion}

Our purpose in this systematic review was to provide an overview of the distinct characteristics of IAs in TSC patients, compared to the healthy population, as well as insight into their pathogenesis. A developmental defect of the arterial wall is the most discussed etiology of aneurysm formation in TSC patients.

\section{Characteristics of IAs in TSC Patients}

In our pooled data, $90.5 \%$ of IAs $(n=38)$ were unruptured. SAH was diagnosed in only 2 patients, and a ruptured aneurysm was found at autopsy in the third patient. All 3 of these patients were young adults, and their ruptured aneurysms were located in the MCA $(\mathrm{n}=1)$, the PCoA (n $=1)$, and the ACA $(n=1)$. One of the aneurysms was saccular, but further information about the size and the form was not reported. In 1 case involving a patient with severe headaches, the aneurysm's rupture status was not reported. 


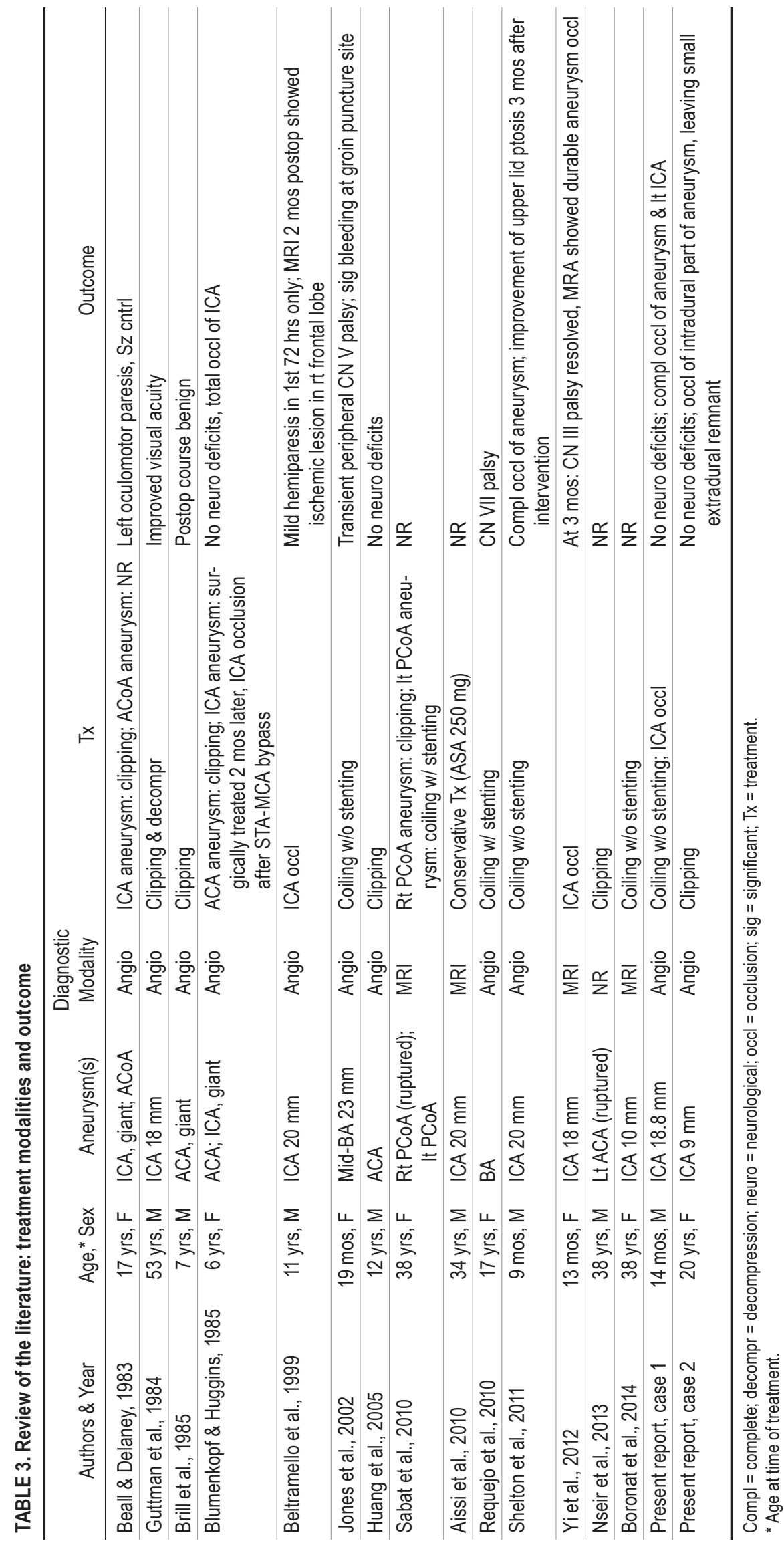


The most common location of IAs was the ICA $(61.9 \%$, $\mathrm{n}=26)$. Most of the IAs were large/giant $(57.1 \%, \mathrm{n}=24)$ and fusiform $(45.2 \%, \mathrm{n}=19)$. Seven of the patients $(21.2 \%)$ presented with multiple IAs. Furthermore, a high male predominance (sex ratio 1.9:1) and a high proportion of pediatric cases $(66.7 \%, \mathrm{n}=22)$ were noticed (mean age of patients was $15.4 \pm 2.5$ years). In summary, IAs in TSC are characterized with distinct demographic, radiological, and clinical features. In particular, only $34.1 \%$ of IAs in the Unruptured Cerebral Aneurysm Study of Japan (UCAS Japan) were located in the ICA; $10.4 \%$ were large/giant and $13.9 \%$ of the patients were found to have multiple IAs. ${ }^{29}$ Moreover, in that study a majority of the patients were female, underscoring a clear difference in the distribution of UIA location, size, and number as well as the patients' sex ratio, compared to our series of TSC patients with IAs.

In TSC patients, IAs were predominantly diagnosed at an early age. In the pediatric cases included in our analysis $(n=22)$, most of the IAs were large/giant $(n=16)$, fusiform $(n=13)$, and located in the ICA $(n=14)$. A higher male predominance in the pediatric group was also noticed (sex ratio 2.5:1). All IAs in pediatric patients were unruptured at the time of diagnosis. Multiple IAs were found substantially more frequently in pediatric patients than in adults (in 6 of 22 pediatric patients vs 1 of 11 adults). The mean age of the pediatric patients was $6.6 \pm 5.2$ years (range $0-17$ years), and $36.3 \%(n=8)$ were 2 years of age or younger. ${ }^{1,18,20,35,37,39,40}$ Even though the initial diagnosis of the IA was at a relative early age, the IAs in these patients were mostly large/giant, so that a rapid aneurysmal growth should be suspected. In the case report of $\mathrm{Yi}$ et al., ${ }^{40}$ as well as in ours (case 1), rapid aneurysmal growth was documented in pediatric patients with TSC, prompting aneurysm treatment despite the patients' young age.

In healthy adults, giant IAs are rare but complex lesions that manifest clinically during the 5th and 6th decades, most frequently in women. ${ }^{13}$ This suggests a very different pattern of growth, compared with the "rapidly growing" IAs in TSC patients. However, analysis of previous reports of large series of pediatric aneurysm cases ${ }^{4}$ indicated several distinct characteristics in the pediatric population, such as male predominance, a disproportionately high number of aneurysms arising from the posterior circulation, high frequency of large/giant aneurysms, high frequency of fusiform aneurysms, and high rate of both ICA and MCA locations among IAs that develop at the anterior circulation. In this way, similarities could be noticed between IAs in TSC patients and those diagnosed in pediatric patients overall including their size and form as well as the high male preponderance. Nevertheless, the predominant location of IAs in TSC patients (ICA), remote from branching zones, remains distinct.

\section{Pathogenesis of IA Development in TSC}

The pathogenesis of IAs in patients with TSC remains to date unclear. Discussion of the evolution of cerebral saccular aneurysms has always focused on the question of the congenital versus the acquired nature of these lesions. This was confounded with many factors, such as familial history of IA and SAH, connective tissue diseases and hypertension, atherosclerosis, etc. ${ }^{19,22}$
In contrast to the well-established natural history of saccular aneurysms as a result of hemodynamic stress, less is known about fusiform aneurysms arising from the arterial trunk unrelated to branching zones. ${ }^{27}$ Consequently, the young age of patients with TSC and the high prevalence of this type of IA in these patients are arguments in favor of a congenital arterial wall anomaly that promotes the development and rapid growth of IAs. Along these lines, Davidson suggested a congenital defect of the arterial wall as a cause of development of IA in these patients. ${ }^{12}$ Beall and Delaney furthered this idea, discussing a developmental defect common to both TSC and ADPKD that would predispose these patients to aneurysm formation. ${ }^{3}$ Blumenkopf and Huggins considered that a coincidental occurrence of multiple IAs in a child is implausible; thus, an arterial defect in this disorder with so many dysplastic features seemed to be obvious. ${ }^{6}$

In 1980, the wall of a UIA in a patient with TSC was histologically analyzed and showed "hypocellular hyaline fibrous tissue, no elastic fibers, no evidence of inflammation or necrosis." 16 Moreover, the microscopic examination at autopsy of an aneurysm of the descending thoracic aorta in a young boy with TSC disclosed an almost complete disappearance of all normal structures. ${ }^{15}$ Some authors have suggested that fusiform aneurysms are correlated with larger aortic root dilatation, suggesting a shared pathophysiological mechanism with aortopathy. ${ }^{9}$ Nevertheless, the true pathogenesis of IAs in TSC patients remains uncertain. Further prospective multicenter studies with larger patient samples and more detailed histological and genetic analyses are needed to better understand IA formation in TSC.

\section{Recommendations}

In the last recommendations of the 2012 International Tuberous Sclerosis Complex Consensus Conference, ${ }^{24}$ the coexistence of IAs with TSC was not mentioned, although 2 cases of SAH in association with TSC were reported. At this conference, MRI was recommended at diagnosis of TSC and every 1 to 3 years until the age of 25 years to screen for development of subependymal giant cell tumors. In the present review, $66.7 \%$ of the reported IA cases involved pediatric patients, and $24.2 \%(8 / 33)$ of the TSC patients with IAs were 2 years of age or younger. A rapid aneurysmal growth, as described in our case 1 and in one of the cases previously reported in the literature ${ }^{40}$ is an important risk factor of aneurysm rupture. Therefore, an enhancement of the above-mentioned regular MRI screenings with cranial TOF-MRA (time-of-flight MR angiography) might be reasonable for TSC patients, particularly for younger individuals.

\section{Limitations of the Study}

The prevalence and the incidence of IA in patients with TSC could not be estimated and may be higher than reported, as most of the publications were retrospective reports and lacked some information. Accordingly, aneurysmal characteristics, treatment management, outcome, and complications of treatment were sometimes not well investigated, so we were unable to comment on the natural history of these aneurysms and risk factors for aneurysm growth and 
rupture or the tendency of developing de novo aneurysms on the basis of our analysis. Despite these limitations, this review still gives insight into this special disease.

\section{Conclusions}

In TSC patients with IAs, there is a higher proportion of large/giant and fusiform IAs in young patients, suggesting a rapid growth of these lesions. In addition, there is a distinct location pattern of IA and an inverse sex ratio compared to that of IA patients without TSC. Large population-based patient registries are required to improve the understanding of the epidemiology and pathophysiology of IA formation in TSC. For timely identification of IA growth, regular MRI screening with TOF-MRA might be reasonable in younger TSC patients.

\section{References}

1. Aeron G, Abruzzo TA, Jones BV: Clinical and imaging features of intracranial arterial aneurysms in the pediatric population. Radiographics 32:667-681, 2012

2. Aissi M, Younes-Mhenni S, Jerbi-Ommezzine S, Boughammoura-Bouatay A, Frih-Ayed M, Sfar MH: [Tuberous sclerosis and intracranial aneurysms: a rare association.] Rev Neurol (Paris) 166:935-939, 2010 (French)

3. Beall S, Delaney P: Tuberous sclerosis with intracranial aneurysm. Arch Neurol 40:826-827, 1983

4. Beez T, Steiger HJ, Hänggi D: Evolution of management of intracranial aneurysms in children: a systematic review of the modern literature. J Child Neurol 31:773-783, 2016

5. Beltramello A, Puppini G, Bricolo A, Andreis IAB, el-Dalati $\mathrm{G}$, Longa L, et al: Does the tuberous sclerosis complex include intracranial aneurysms? A case report with a review of the literature. Pediatr Radiol 29:206-211, 1999

6. Blumenkopf B, Huggins MJ: Tuberous sclerosis and multiple intracranial aneurysms: case report. Neurosurgery 17:797800,1985

7. Boronat S, Shaaya EA, Auladell M, Thiele EA, Caruso P: Intracranial arteriopathy in tuberous sclerosis complex. J Child Neurol 29:912-919, 2014

8. Brill CB, Peyster RG, Hoover ED, Keller MS: Giant intracranial aneurysm in a child with tuberous sclerosis: CT demonstration. J Comput Assist Tomogr 9:377-380, 1985

9. Can A, Xu J, Volovici V, Dammers R, Dirven CM, MacRae $\mathrm{CA}$, et al: Fusiform aneurysms are associated with aortic root dilatation in patients with subarachnoid hemorrhage. World Neurosurg 84:1681-1685, 2015

10. Chen YL, Luo CB, Hsu SW, Rodesch G, Lasjaunias P: Tuberous sclerosis complex with an unruptured intracranial aneurysm: manifestations of contiguous gene syndrome. Interv Neuroradiol 7:337-341, 2001

11. Copley DJ: Case of the season. Semin Roentgenol 20:107109, 1985

12. Davidson S: Tuberous sclerosis with fusiform aneurysms of both internal carotid arteries manifested by unilateral visual loss and papilledema. Bull Los Angeles Neurol Soc 39:128132,1974

13. dos Santos MLT, Spotti AR, dos Santos RMT, Borges MA, Ferrari AF, Colli BO, et al: Giant intracranial aneurysms: morphology and clinical presentation. Neurosurg Rev 36:117-122, 2013

14. Gomez MR: Criteria for diagnosis, in Tuberous Sclerosis. New York: Raven Press, 1988

15. Guttman M, Tanen SM, Lambert CD: Visual loss secondary to a giant aneurysm in a patient with tuberous sclerosis. Can J Neurol Sci 11:472-474, 1984
16. Ho KL: Intraventricular aneurysm associated with tuberous sclerosis. Arch Neurol 37:385-386, 1980

17. Huang J, McGirt MJ, Gailloud P, Tamargo RJ: Intracranial aneurysms in the pediatric population: case series and literature review. Surg Neurol 63:424-433, 2005

18. Hung PC, Wang HS, Chou ML, Wong AMC: Tuberous sclerosis complex with multiple intracranial aneurysms in an infant. Pediatr Neurol 39:365-367, 2008

19. Jabbarli R, Dinger TF, Darkwah Oppong M, Pierscianek D, Dammann P, Wrede KH, et al: Risk factors for and clinical consequences of multiple intracranial aneurysms: a systematic review and meta-analysis. Stroke 49:848-855, 2018

20. Jones BV, Tomsick TA, Franz DN: Guglielmi detachable coil embolization of a giant midbasilar aneurysm in a 19-monthold patient. AJNR Am J Neuroradiol 23:1145-1148, 2002

21. Jurkiewicz E, Jóźwiak S: Giant intracranial aneurysm in a 9-year-old boy with tuberous sclerosis. Pediatr Radiol 36:463, 2006

22. Juvela S, Porras M, Poussa K: Natural history of unruptured intracranial aneurysms: probability of and risk factors for aneurysm rupture. J Neurosurg 93:379-387, 2000

23. Koroknay-Pál P, Lehto H, Niemelä M, Kivisaari R, Hernesniemi J: Long-term outcome of 114 children with cerebral aneurysms. J Neurosurg Pediatr 9:636-645, 2012

24. Krueger DA, Northrup H, Roberds S, Smith K, Sampson J, Korf B, et al: Tuberous sclerosis complex surveillance and management: recommendations of the 2012 International Tuberous Sclerosis Complex Consensus Conference. Pediatr Neurol 49:255-265, 2013

25. Longa L, Scolari F, Brusco A, Carbonara C, Polidoro S, Valzorio B, et al: A large TSC2 and PKD1 gene deletion is associated with renal and extrarenal signs of autosomal dominant polycystic kidney disease. Nephrol Dial Transplant 12:1900-1907, 1997

26. Martin N, de Broucker T, Cambier J, Marsault C, Nahum $\mathrm{H}$ : MRI evaluation of tuberous sclerosis. Neuroradiology 29:437-443, 1987

27. Mizutani T, Miki Y, Kojima H, Suzuki H: Proposed classification of nonatherosclerotic cerebral fusiform and dissecting aneurysms. Neurosurgery 45:253-260, 1999

28. Moher D, Liberati A, Tetzlaff J, Altman DG: Preferred reporting items for systematic reviews and meta-analyses: the PRISMA statement. Int J Surg 8:336-341, 2010

29. Morita A, Kirino T, Hashi K, Aoki N, Fukuhara S, Hashimoto $\mathrm{N}$, et al: The natural course of unruptured cerebral aneurysms in a Japanese cohort. N Engl J Med 366:2474-2482, 2012

30. Northrup H, Krueger DA, Roberds S, Smith K, Sampson J, Korf B, et al: Tuberous sclerosis complex diagnostic criteria update: recommendations of the 2012 International Tuberous Sclerosis Complex Consensus Conference. Pediatr Neurol 49:243-254, 2013

31. Nseir G, Golshayan D, Barbey F: Phenytoin-associated severe hypocalcemia with seizures in a patient with a TSC2-PKD1 contiguous gene syndrome. Ren Fail 35:866-868, 2013

32. Osborne JP, Fryer A, Webb D: Epidemiology of tuberous sclerosis. Ann N Y Acad Sci 615:125-127, 1991

33. Requejo F, Ceciliano A, Cardenas R, Villasante F, Jaimovich R, Zuccaro G: Cerebral aneurysms in children: are we talking about a single pathological entity? Childs Nerv Syst 26:1329-1335, 2010

34. Sabat SB, Cure J, Sullivan J, Gujrathi R: Tuberous sclerosis with multiple intracranial aneurysms: atypical tuberous sclerosis diagnosed in adult due to third nerve palsy. Acta Neurol Belg 110:89-92, 2010

35. Shelton JB, Ramakrishnaiah R, Glasier CM, Phillips PH: Cavernous sinus syndrome from an internal carotid artery aneurysm in an infant with tuberous sclerosis. J AAPOS 15:389-391, 2011 
36. Snowdon JA: Cerebral aneurysm, renal cysts and hamartomas in a case of tuberous sclerosis. Br J Urol 46:583, 1974

37. Spangler WJ, Cosgrove GR, Moumdjian RA, Montes JL: Cerebral arterial ectasia and tuberous sclerosis: case report. Neurosurgery 40:191-194, 1997

38. Swarnkar A, Jungreis CA, Peel RL: Central odontogenic fibroma and intracranial aneurysm associated with tuberous sclerosis. Am J Otolaryngol 19:66-69, 1998

39. Wang B, Tu YF, Tsai YS: Teaching NeuroImages: Huge carotid artery aneurysm in TSC2/PKD1 contiguous gene syndrome. Neurology 89:e93-e94, 2017

40. Yi JL, Galgano MA, Tovar-Spinoza Z, Deshaies EM: Coil embolization of an intracranial aneurysm in an infant with tuberous sclerosis complex: a case report and literature review. Surg Neurol Int 3:129, 2012

\section{Disclosures}

The authors report no conflict of interest concerning the materi- als or methods used in this study or the findings specified in this paper.

\section{Author Contributions}

Conception and design: Chihi, Jabbarli. Acquisition of data: Chihi. Analysis and interpretation of data: all authors. Drafting the article: Chihi. Critically revising the article: all authors. Reviewed submitted version of manuscript: Chihi, Sure, Jabbarli. Approved the final version of the manuscript on behalf of all authors: Chihi. Statistical analysis: Chihi. Administrative/technical/material support: Chihi. Study supervision: Sure, Jabbarli.

\section{Correspondence}

Mehdi Chihi: University Hospital Essen, University of DuisburgEssen, Essen, Germany. mehdi.chihi@uk-essen.de. 


\title{
Vasospasm-related complications after subarachnoid hemorrhage: the role of patients' age and sex
}

\author{
Marvin Darkwah Oppong ${ }^{1} \cdot$ Antonella lannaccone $^{2} \cdot$ Oliver Gembruch $^{1} \cdot$ Daniela Pierscianek $^{1} \cdot$ Mehdi Chihi $^{1}$. \\ Philipp Dammann ${ }^{1} \cdot$ Angela Köninger $^{2} \cdot$ Oliver Müller $^{1} \cdot$ Michael Forsting $^{3} \cdot$ Ulrich Sure $^{1} \cdot$ Ramazan Jabbarli $^{1}$
}

Received: 10 January 2018 / Accepted: 11 April 2018

(C) Springer-Verlag GmbH Austria, part of Springer Nature 2018

\begin{abstract}
Background Outcome of aneurysmal subarachnoid hemorrhage (SAH) depends strongly on occurrence of symptomatic vasospasm (SV) leading to delayed cerebral ischemia (DCI). Various demographic, radiographic, and clinical predictors of SV have been reported so far, partially with conflicting results. The aim of this study was to analyze the role of patients' age and sex on SV/ DCI risk, especially to identify age and sex-specific risk groups.

Methods All patients admitted with acute SAH during a 14-year-period ending in 2016 were eligible for this study. The study endpoints were the following: SV requiring spasmolysis, occurrence of DCI in follow-up computed tomography scans and unfavorable outcome at 6 months (modified Rankin scale $>2$ ).

Results Nine hundred ninety-four patients were included in this study. The majority was female $(666 ; 67 \%)$. SV, DCI, and unfavorable outcomes were observed in $21.5,21.8$, and $43.6 \%$ of the patients, respectively. Younger age $(p<0.001 ;$ OR $=1.03$ per year decrease) and female sex $(p=0.025 ; \mathrm{OR}=1.510)$ were confirmed as independent predictors of SV. Regarding the sex differences, there were three age groups for SV/DCI risk $\leq 54,55-74$, and $\geq 75$ years. Male patients showed earlier decrease in SV risk (at $\geq 55$ vs. $\geq 75$ years in females). Therefore, SAH females aged between 55 and 74 years were at the highest risk for DCI and unfavorable outcome, as compared to younger/older females $(p=0.001, \mathrm{OR}=1.77 / p=0.001, \mathrm{OR}=1.80)$. In contrast, their male counterparts did not show these risk alterations $(p=0.445 / p=0.822)$.

Conclusion After acute SAH, female and male patients seem to show different age patterns for the risk of SV and DCI. Females aged between 55 and 74 years are at particular risk of vasospasm-related SAH complications, possibly due to onset of menopause.

Clinical trial registration number DRKS, Unique identifier: DRKS00008749
\end{abstract}

Keywords Symptomatic vasospasm $\cdot$ Aneurysm $\cdot$ Subarachnoid hemorrhage $\cdot$ Delayed cerebral ischemia $\cdot$ Age dependency $\cdot$ Sex dependency

\section{Abbreviations}

CI 95\% Confidence interval 95\%

CT Computed tomography

DCI Delayed cerebral ischemia

ICH Intracerebral hemorrhage

Marvin Darkwah Oppong

marvindarkwah.oppong@uk-essen.de

1 Department of Neurosurgery, University Hospital, University of Duisburg-Essen, 45147 Essen, Germany

2 Department of Gynecology and Obstetrics, University Hospital, University of Duisburg-Essen, Essen, Germany

3 Institute for Diagnostic and Interventional Radiology, University Hospital, University of Duisburg-Essen, Essen, Germany

$\begin{array}{ll}\text { IVH } & \text { Intraventricular hemorrhage } \\ \text { mRS } & \text { Modified Rankin scale } \\ \text { OR } & \text { Odds ratio } \\ \text { SAH } & \text { Subarachnoid hemorrhage } \\ \text { SD } & \text { Standard deviation } \\ \text { SV } & \text { Symptomatic vasospasm } \\ \text { TCD } & \text { Transcranial Doppler ultrasound } \\ \text { WFNS } & \text { World Federation of Neurosurgical Societies }\end{array}$

\section{Introduction}

Delayed cerebral ischemia (DCI) remains one of the key factors influencing the outcome after aneurysmal subarachnoid hemorrhage (SAH) [23]. Even though 
development of DCI is complex and starts at ictus, the occurrence of symptomatic vasospasm (SV) is still recognized as the major contributor to DCI [12].

The amount of intracranial bleeding is probably the strongest determinant of vasospasm-related ischemic complications of SAH $[5,11,13]$. Moreover, the value of demographic characteristics of patients for probability of SV has also been disputed intensively $[17,18,27,28,39]$. In particular, several authors reported lower risk of SV in elderly patients, however, with conflicting results and different age cutoffs $[4,37,39]$.

Female sex is a widely accepted risk factor for development and rupture of intracranial aneurysms [48]. There have been conflicting reports about the influence of female sex on development of SV and DCI [4, 22, 37-39, 51].

Even less is known about interactions between age and sex in risk of SV. To date, there is only one recent study that addressed sex differences in age-dependent risk of DCI after SAH [14].

The aim of this study was to analyze the role of patients' age and sex on risk of SV and DCI after SAH, with the special attention to possible sex-specific patterns in different age groups.

\section{Material and methods}

Patients admitted at our institution between January 2003 and June 2016 with acute aneurysmal SAH were eligible for this retrospective study. The study was approved by the Institutional Review Board (Ethik-Kommission, Medizinische Fakultät der Universität Duisburg-Essen, Registration number: 15-6331$\mathrm{BO}$ ), and registered in the German clinical trial registry (DRKS, Unique identifier: DRKS00008749).

The clinical management included transcranial Doppler ultrasound (TCD) at least once daily for 14 days and oral administration of nimodipine for 21 days after onset of SAH. Acute hydrocephalus was treated by placement of an external ventricular or lumbar drainage. All patients received an early post treatment computed tomography (CT) of the head in the first $24 \mathrm{~h}$ post treatment. Additional CT scans were performed, if clinically indicated.

Demographic, clinical, and radiographic data of the patients were collected from an electronic medical database. Clinical condition on admission was graded according to the World Federation of Neurosurgical Societies (WFNS) grading system [47]. For statistical analysis, the WFNS scale was dichotomized into good (1-3) and poor (4-5) grades. Radiographic severity of SAH was assessed using the original Fisher scale [11], with further dichotomization in high (3-4) and low (1-2) grades. In addition, the presence of intraventricular (IVH) and intracerebral hemorrhage (ICH) on admission CT scan was also documented. We evaluated clinical condition at 6-month follow-up using the modified Rankin scale (mRS) [49]. Unfavorable functional outcome was defined as $\mathrm{mRS}>2$.

Judgment about the presence of SV was made upon the following criteria: (a) occurrence of neurological deterioration (new focal neurological deficit and/or decrease in Glasgow Coma Scale $>1$ point), (b) exclusion of other causes of neurological worsening (such as re-bleeding or hydrocephalus) by a follow-up CT scan, (c) TCD observations suspicious for vasospasm $(>120 \mathrm{~cm} / \mathrm{c}$ ), (d) confirmation of vasospasm on digital subtraction angiography (DSA). All patients with persistent SV underwent spasmolysis using intra-arterial application of nimodipine and, if necessary, percutaneous transluminal balloon angioplasty.

We reviewed all follow-up CT scans during hospitalization after SAH with regard to occurrence of cerebral infarctions that is not resulted from ICH, surgical approach, or ventricular catheter placement. Infarcts documented $>48 \mathrm{~h}$ after early aneurysm occlusion were defined as delayed cerebral ischemia (DCI) as according to the definition of Vergouwen et al. [50].

\section{Data management and statistics}

The study endpoints were the risk factors for SV requiring spasmolysis, DCI, and unfavorable outcome. The data analysis was performed using SPSS for Mac Version 22 (IBM Corp.). Continuous variables were given in mean \pm standard deviation (SD). The patients' age was analyzed both as continuous and as categorical variable (using multiple testing procedures). The associations between variables were evaluated in univariate and multivariate manner. Categorical variables were analyzed using the Chi-Square test, for samples smaller than five the Fisher-Exact test was used. Continuous variables were analyzed using the Student's $t$ test for normally distributed and the Mann-Whitney $U$ test for non-normally distributed data. Multivariate analysis was performed using binary regression analyses. $P<0.05$ was considered statistically significant.

\section{Results}

A total of 994 patients were included in this study. The majority was female $(666 ; 67 \%)$; the mean age at presentation was $55 \pm 14$ years. $43.2 \%$ of the patients presented in poor initial clinical condition, and $86.5 \%$ in Fisher grades 3 or 4 . IVH was observed in $48.2 \%$ and ICH in $31.1 \%$ of the patients. Treatment of acute hydrocephalus was necessary in $67.1 \%$ of the cases. Over half of the patients $(58.5 \%)$ were treated by coil embolization. Two hundred fourteen $(21.5 \%)$ patients underwent spasmolysis for SV; DCI was documented in 197 patients $(21.8 \%)$. In-hospital mortality rate was $18.1 \%$. Unfavorable outcome at 6 months post-SAH was observed in $43.6 \%$ of the cohort. 


\section{Predictors of SV, DCI, and outcome}

In multivariate analysis, the occurrence of SV was independently predicted by younger age $(p<0.001$; odds ratio $(\mathrm{OR})=$ 1.03 per year decrease; confidence interval $95 \%$ (CI 95\%) $1.01-1.05)$, female sex $(p=0.025 ; \mathrm{OR}=1.510 ;$ CI $95 \%$ $1.05-2.17)$, good clinical condition at admission $(p=0.027$; $\mathrm{OR}=1.47$; CI 95\% 1.04-2.08), high Fisher grade ( $p=0.028$; $\mathrm{OR}=1.98$; CI $95 \% 1.08-3.7)$, and acute hydrocephalus $(p<0.001 ; \mathrm{OR}=2.82 ; \mathrm{CI} 95 \% 1.80-4.42)$. DCI was independently predicted by acute hydrocephalus at admission $(p<0.001 ; \mathrm{OR}=3.51 ; \mathrm{CI} 95 \% 2.03-6.07)$ and poor initial clinical condition $(p=0.038$; OR $=1.47$; CI 95\% 1.02-2.10, Table 2). Unfavorable outcome was independently predicted by high Fisher grade $(p=0.003$; OR $=3.33$; CI 95\% 1.49 $7.44)$, poor WFNS score $(p<0.001$; OR $=5.64$; CI $95 \%$ $3.84-8.26)$, higher age $(p<0.001 ; \mathrm{OR}=1.04$, per year of age increase; CI 95\% 1.03-1.06), and acute hydrocephalus $(p<0.001 ; \mathrm{OR}=2.26$; CI 95\% 1.46-3.50, Table 2).

Finally, all three study endpoints showed a strong correlation with each other: $p<0.001$; OR $=3.27$ for SV and DCI, $p=0.013 ; \mathrm{OR}=1.52$ for $\mathrm{SV}$ and unfavorable outcome, $p<0.001$; OR $=8.04$ for DCI and unfavorable outcome. Whereas treatment modalities showed no correlation with SV and DCI $(p=0.423$ and $p=0.420)$.

\section{Differences between males and females: baseline parameters}

In our cohort, female patients were significantly older (mean age 53 vs. 56 years; $p=0.013$ ). There were no significant differences regarding the initial severity of $\mathrm{SAH}$, treatment modalities, and clinical and radiographic outcome between the sexes (see Tables 1 and 2).

\section{Association between age and sex for SV risk}

When analyzing the association between SV and patients' age separately for males and females, the following age groups could be identified: " $\leq 54$ years," "55-74 years" and " $\geq$ 75 years" (Fig. 1). For both sexes uniformly, younger patients aged $<55$ years were at significantly higher risk for $\mathrm{SV}$ than the older counterparts: $p=0.001$ (OR $=1.84$; CI 95\% 1.28$2.67)$ and $p=0.003(\mathrm{OR}=2.63$; CI $95 \% 1.38-5.01)$ for females and males, respectively. However, there were different sex-specific alterations of SV risk in the age groups "5574 years" and " $\geq 75$ years." For male patients, the risk declined in the group " $55-74$ years" $(p=0.007$; OR $=0.39$; CI 95\% 0.20-0.79) and showed no further alteration in the eldest age group (" $\geq 75$ years," $p=0.590$ ). In contrast, there was no difference in SV risk between the age groups " $\leq 54$ years" and "55-74 years" in female patients $(p=0.146)$, whereat the significant decrease was observed only in the group " $\geq 75$ years" $(p=0.002 ; \mathrm{OR}=0.25 ; \mathrm{CI} 95 \% 0.10-0.64)$. Accordingly, there was a significant difference between the sexes in the risk of SV in the age group " $55-74$ years" $-p=0.016 ; \mathrm{OR}=2.29$ (CI 95\% $1.15-4.58 \%)$ for female SAH patients $(p=0.191$ and $p=0.611$ in the age groups " $\leq 54$ years" and " $\geq 75$ years," respectively). In this specific age group for both sexes, no correlation of treatment modalities and SV risk could be shown $(p=0.672$ and $p=0.583$ for female and male patients, respectively).

\section{The role of sex-specific age groups for DCI risk}

In male patients, there were no significant differences in the above-mentioned age groups regarding DCI risk (see Appendix Table 3). Where as in female patients, the risk of DCI was the highest in the group "55-74 years" $(p=0.001$; $\mathrm{OR}=1.77$; CI 95\% 1.20-2.63, Fig. 2). However, this risk did not correlate with treatment modalities in this group $(p=0.082)$.

\section{The role of sex-specific age groups for functional outcome}

There was a stepwise increase in the risk of unfavorable outcome in the three age groups in both sexes. However, the functional outcome of male patients in the age group "55-74 years" did not differ significantly from younger or older males $(p=0.445)$. In contrast, female patients aged "55-74 years" had significantly poorer outcome, as compared to younger or older females in our cohort $(p=$ 0.001; OR $=1.80$; CI 95\% 1.25-2.59, Fig. 3, Appendix Fig. 4 for all age groups).

\section{Discussion}

The aim of this study was to investigate the role of age and sex on the risk of vasospasm-related complications after SAH. Alongside with initial clinical and radiographic severity of SAH, patients' age and sex could be confirmed as independent predictors of SV. Moreover, we identified different age patterns for vasospasm risk in female and male patients. Accordingly, female SAH patients aged between 55 and 74 years were at particular risk for SV, DCI, and unfavorable functional outcome. A treatment modality dependent risk for SV and DCI as reported by some authors $[10,15]$ could not be shown in our cohort and for the subgroup of women between 55 and 74 years.

\section{SV and DCI after SAH: common predictors}

Our results for vasospasm predictors are in line with the majority of previous reports [11, 13, 17, 37]. The amount of intracranial bleeding is probably the most frequently reported risk factor for SV and DCI $[5,11,13]$. Regarding 
Table 1 Overview over demographic and clinical parameters divided by sexes and univariate analysis

\begin{tabular}{|c|c|c|c|c|c|c|c|}
\hline Parameter & Male ( $n /$ mean $)$ & $\% / \mathrm{SD}$ & Female ( $n /$ mean $)$ & $\% / \mathrm{SD}$ & $p$ & OR & CI $95 \%$ \\
\hline Age (years) & 53 & \pm 14 & 56 & \pm 14 & 0.013 & & \\
\hline WFNS 4-5 & 143 & $43.6 \%$ & 286 & $42.9 \%$ & 0.845 & 0.97 & $0.75-1.27$ \\
\hline Fisher $3-4 *$ & 260 & $87.5 \%$ & 519 & $85.9 \%$ & 0.505 & 0.87 & $0.57-1.31$ \\
\hline Treatment coiling $\dagger$ & 187 & $57.0 \%$ & 393 & $62.1 \%$ & 0.601 & 0.93 & $0.70-1.23$ \\
\hline Sack size (mm) & 7,21 & \pm 4.58 & 7,45 & \pm 4.82 & 0.476 & & \\
\hline Acute hydrocephalus & 219 & $68.7 \%$ & 440 & $68.5 \%$ & 0.971 & 0.99 & $0.75-1.33$ \\
\hline IVH $\S$ & 165 & $50.6 \%$ & 312 & $47.1 \%$ & 0.293 & 0.87 & $0.67-1.13$ \\
\hline ICB II & 108 & $32.9 \%$ & 200 & $30.2 \%$ & 0.377 & 0.88 & $0.66-1.17$ \\
\hline SV & 59 & $18.0 \%$ & 155 & $23.3 \%$ & 0.057 & 1.38 & $0.99-1.93$ \\
\hline DCIपI & 68 & $20.7 \%$ & 129 & $21.3 \%$ & 0.645 & 0.93 & $0.66-1.29$ \\
\hline Unfavorable outcome ${ }^{\#}$ & 111 & $45.6 \%$ & 217 & $42.6 \%$ & 0.431 & 1.13 & $0.82-1.54$ \\
\hline In-hospital mortality & 62 & $18.9 \%$ & 118 & $17.7 \%$ & 0.648 & 0.92 & $0.66-1.30$ \\
\hline
\end{tabular}

*93 initial CT not available

$\dagger 51$ patients with no treatment

\$Data missing for 33 patients

$\S$ Data missing for 5 patients

${ }^{\text {II }}$ Data missing for 3 patients

${ }^{\mathbb{I}}$ No follow-up CT in 89 patients due to early death

${ }^{\#}$ Follow-up data available for 752 patients

the initial clinical severity of $\mathrm{SAH}$, the results are less consistent $[4,16,17,27,29,30]$. Our data are in agreement with the article of Charpentier et al. [4] who reported about higher incidence of SV in SAH individuals with good initial clinical condition. This association might be due to higher probability to overlook the occurrence of $\mathrm{SV}$ in patients with poor initial clinical presentation.

The younger age is widely accepted as a predictor of SV [4, 26, 37]. Some authors tried to answer the question of pathogenesis of this correlation. Magge et al. [28] supposed that increasing stiffness of the cerebral vasculature associated with advancing age may explain the lower incidence of angiographic vasospasm in the elderly. The possible role of atherosclerosis in the impaired contractility and elasticity of small arteries and arterioles in elderly persons was debated as well $[6,31]$.
But there are also negative reports on the correlation of younger age with SV incidence [2, 39].

Female sex is a recognized risk factor for the occurrence of aneurysmal SAH [22]. Perhaps for this reason, there were many attempts to find out, whether female sex is also predictive for SV. Thus, some authors [38, 39] reported about significantly higher incidence of angiographic vasospasm in females. However, in the majority of later publications, the (female) sex could not show any predictive value $[4,37,51]$.

\section{Different age patterns for vasospasm risk in males and females}

In our cohort, both sexes showed a decrease in SV incidence with increasing age. Male patients showed an earlier decline of SV incidence after reaching the cohort's median age (55 years).

Table 2 Multivariate analysis of predictors of DCI and unfavorable outcome

\begin{tabular}{|c|c|c|c|c|c|c|}
\hline \multirow[t]{2}{*}{ Parameter } & \multicolumn{3}{|l|}{ DCI } & \multicolumn{3}{|c|}{ Unfavorable outcome } \\
\hline & $p$ & OR & CI $95 \%$ & $p$ & OR & CI $95 \%$ \\
\hline Age (years) & 0.861 & 1.00 & $0.99-1.01$ & $<0.001$ & 1.04 & $1.03-1.06$ \\
\hline Female sex & 0.895 & 1.03 & $0.71-1.47$ & 0.251 & 0.79 & $0.54-1.18$ \\
\hline Fisher 3-4 & 0.367 & 1.38 & $0.68-2.80$ & 0.003 & 3.33 & $1.49-7.44$ \\
\hline WFNS 4-5 & 0.038 & 1.47 & $1.02-2.10$ & $<0.001$ & 5.64 & $3.84-8.26$ \\
\hline Acute hydrocephalus & $<0.001$ & 3.51 & $2.03-6.07$ & $<0.001$ & 2.26 & $1.46-3.50$ \\
\hline
\end{tabular}




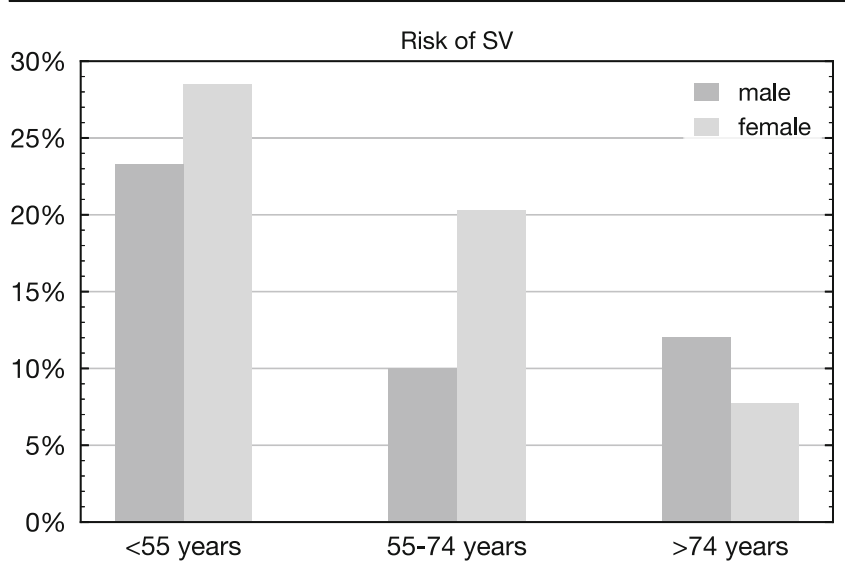

Fig. 1 Age-dependent risk of the development of SV divided in three age groups $(\leq 55,55-74$, and $\geq 74$ years). The risk is given in percent and compared to the risk for younger/older same sex counterparts

By contrast, SV risk persisted in the subgroup of females aged between 55 and 74 years. Accordingly, there was a significantly higher risk of SV in female patients (than in male counterparts) only in this age group. In addition, females aged between 55 and 74 years were at higher risk for DCI and unfavorable outcome, as compared to younger or older SAH females. One large recent study has reported that female sex itself increases the risk of DCI but failed to prove an age dependency [14].

High prevalence of vasospasm complications after SAH in females aged between 55 and 74 years may have several explanations. One strong point is the changed sex hormone situation of women at this age. Women over 55 could be considered as postmenopausal [34], the median age for onset of the menopausal state is reported to be 51-52 years in larger European studies [35, 43]. Therefore, the above-described eminent risk for vasospasm complications after SAH in females in sixth-seventh life-decades might be partially due to postmenopausal hormonal changes. The loss of estrogen has been connected to the risk of aneurysm development and

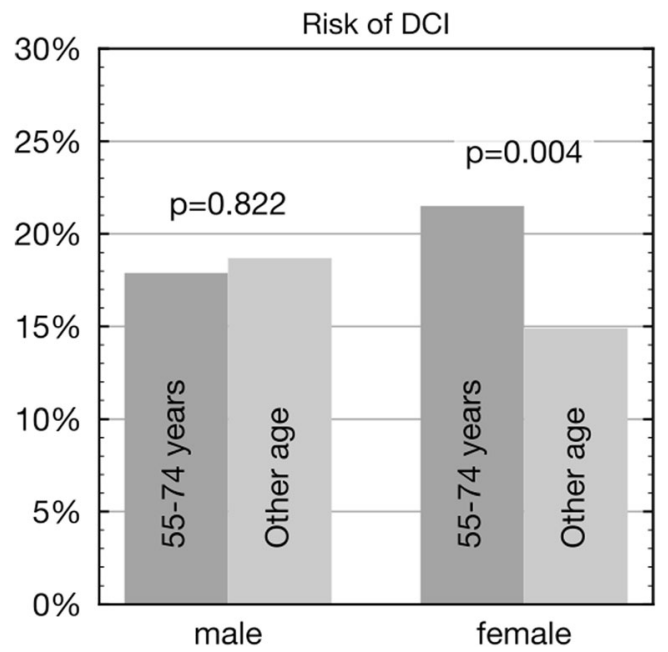

Fig. 2 DCI risk in the age group "55-74 years" compared with the same sex younger/older counterparts. Risk is given in percent

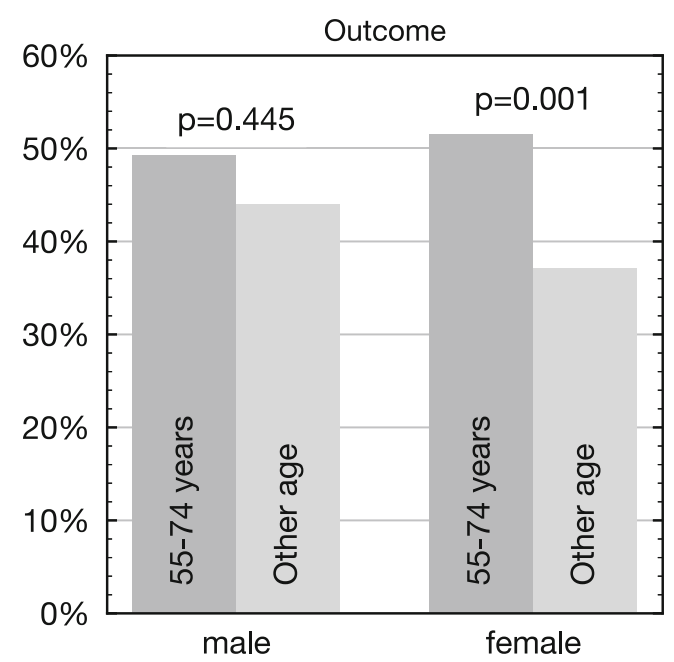

Fig. 3 Risk for unfavorable outcome in percent the age group "5574 years" compared with the same sex younger/older counterparts

rupture [19, 44-46]. Moreover, it has been shown that estradiol reduces vasospasm in rat models [24, 25, 41]. Estradiol has direct vasodilator effects via enhancing endothelial nitric oxide production and its bioavailability over activation of endothelial nitric oxide synthase [42]. In addition, it reduces the expression of Endothelin-1 and inducible nitric oxide synthase, both connected to vasospasm in SAH $[24,41]$.

Besides the vasodilatory effect of estrogen, it might reduce the risk of arteriosclerosis [33]. In turn, atherosclerosis itself decreases the contractibility of intracranial vessels $[6,28]$. This circumstance could also contribute to the role of estrogen on SV risk. Later onset of atherosclerosis leads to a longer preserved plasticity of the intracranial vessels in women which declines postmenopausal [3]. However, full effects of estrogen defiance can be observed many years after the last hormonal-triggered menstrual bleeding. This is in concordance with a SV risk decline only seen after the age of 75 years.

Due to increased risk of symptomatic vasospasm and its ischemic complications in the post-menopausal age, it may become pivotal to assess the hormonal status of female SAH patients and, if necessary, to derive therapeutic consequences. Positive impact of hormonal replacement therapy could be demonstrated in neurocritical experimental studies with acute stroke and traumatic brain injury [20, 21, 40].

\section{Limitations}

The major limitation of this study is its retrospective nature. Accordingly, we had no data directly reflecting the hormonal condition of female SAH patients in our cohort. Therefore, occurrence of postmenopausal state was judged upon the patients' age. This approach elides large variability in the onset of 
menopause [9], the probability of premature menopause/ premature ovarian failure [7] or iatrogenic induced menopausal (due to chemotherapy, surgery, etc.) [32]. These data would be of particular interest, since early menopause has been reported to be a risk factor for aneurysm development [8]. Moreover, we could not include any data regarding hormone replacement therapy or use of oral contraceptives. Both have been reported to have an impact on the risk of aneurysm rupture $[1,36]$.

\section{Conclusion}

After acute SAH, female and male patients seem to show different age patterns for the risk of SV, DCI, and unfavorable outcome. SAH females aged between 55 and 74 years are at particular risk of vasospasm-related complications, possibly due to onset of menopausal state in this age. Our data prompt to further clinical and experimental investigations of the role of female sexual hormones on vasospasm risk after SAH.

\section{Compliance with ethical standards}

Conflict of Interest All authors certify that they have no affiliations with or involvement in any organization or entity with any financial interest (such as honoraria; educational grants; participation in speakers' bureaus; membership, employment, consultancies, stock ownership, or other equity interest; and expert testimony or patent-licensing arrangements), or non-financial interest (such as personal or professional relationships, affiliations, knowledge, or beliefs) in the subject matter or materials discussed in this manuscript.

Ethical approval All procedures performed in studies involving human participants were in accordance with the ethical standards of the institutional and/or national research committee and with the 1964 Helsinki declaration and its later amendments or comparable ethical standards. For this type of study formal consent is not required.

\section{Appendix}

Table 3 Age-dependent risk for DCI divided by sex groups

\begin{tabular}{|c|c|c|c|c|c|c|c|c|}
\hline \multirow[t]{2}{*}{ Age (years) } & \multicolumn{4}{|l|}{ Male } & \multicolumn{4}{|l|}{ Female } \\
\hline & Rate of DCI (\%) & $p$ & OR & $95 \% \mathrm{CI}$ & Rate of DCI (\%) & $p$ & OR & $95 \% \mathrm{CI}$ \\
\hline$\leq 54$ & 21.2 & 0.443 & 0.81 & $0.47-1.30$ & 19.2 & 0.190 & 0.77 & $0.52-1.14$ \\
\hline $55-74$ & 21.9 & 0.822 & 0.94 & $0.52-1.68$ & 27.4 & 0.004 & 1.77 & $1.20-2.63$ \\
\hline$\geq 75$ & 40.0 & 0.092 & 2.44 & $0.96-6.25$ & 8.0 & 0.009 & 0.27 & $0.10-0.77$ \\
\hline
\end{tabular}

Fig. 4 Sex-dependent risk for unfavorable outcome in the three different age groups $(\leq 55,55-74$, and $\geq 74$ years) in percent. And comparison with the same sex younger/older counterparts

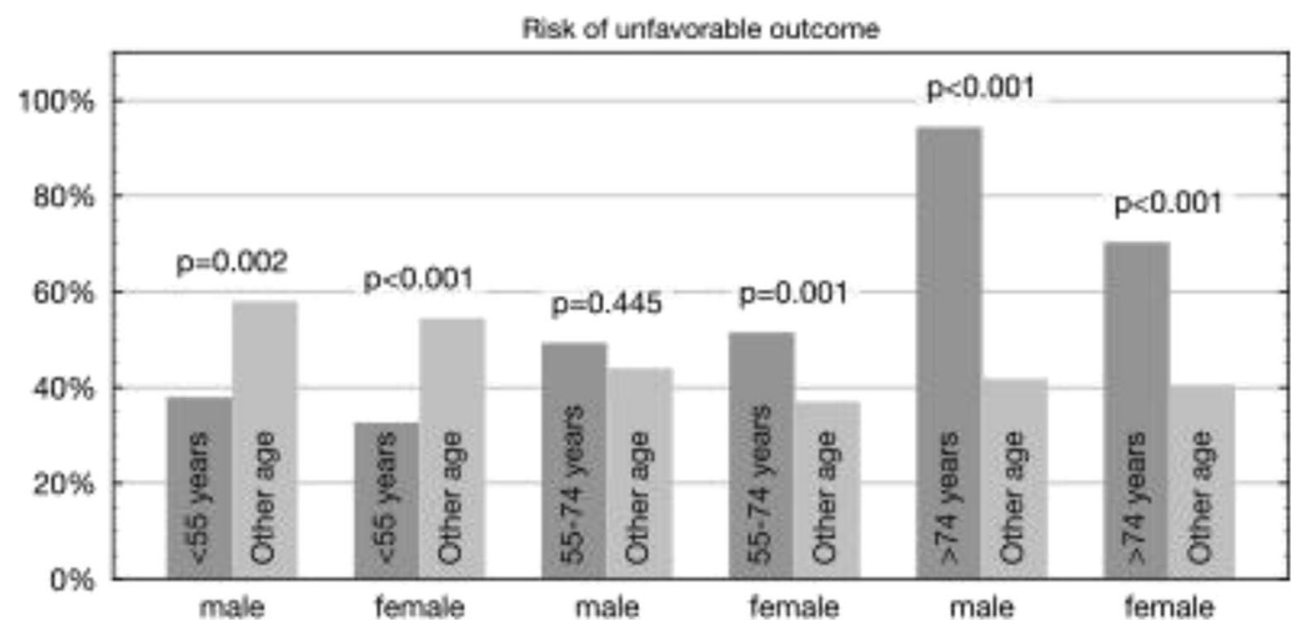




\section{References}

1. Algra AM, Klijn CJ, Helmerhorst FM, Algra A, Rinkel GJ (2012) Female risk factors for subarachnoid hemorrhage: a systematic review. Neurology 79:1230-1236. https://doi.org/10.1212/WNL. 0b013e31826aace6

2. Anderson RC, Kan P, Klimo P, Brockmeyer DL, Walker ML, Kestle JR (2004) Complications of intracranial pressure monitoring in children with head trauma. J Neurosurg 101:53-58. https://doi. org/10.3171/ped.2004.101.2.0053

3. Calleja-Agius J, Brincat M (2012) The effect of menopause on the skin and other connective tissues. Gynecol Endocrinol 28:273-277. https://doi.org/10.3109/09513590.2011.613970

4. Charpentier C, Audibert G, Guillemin F, Civit T, Ducrocq X, Bracard S, Hepner H, Picard L, Laxenaire MC (1999) Multivariate analysis of predictors of cerebral vasospasm occurrence after aneurysmal subarachnoid hemorrhage. Stroke 30: $1402-1408$

5. Claassen J, Bernardini GL, Kreiter K, Bates J, Du YE, Copeland D, Connolly ES, Mayer SA (2001) Effect of cisternal and ventricular blood on risk of delayed cerebral ischemia after subarachnoid hemorrhage: the Fisher scale revisited. Stroke 32:2012-2020

6. Claus JJ, Breteler MM, Hasan D, Krenning EP, Bots ML, Grobbee DE, Van Swieten JC, Van Harskamp F, Hofman A (1998) Regional cerebral blood flow and cerebrovascular risk factors in the elderly population. Neurobiol Aging 19:57-64

7. de Moraes-Ruehsen M, Jones GS (1967) Premature ovarian failure. Fertil Steril 18:440-461

8. Ding C, Toll V, Ouyang B, Chen M (2013) Younger age of menopause in women with cerebral aneurysms. J Neurointerv Surg 5: 327-331. https://doi.org/10.1136/neurintsurg-2012-010364

9. Dratva J, Gomez Real F, Schindler C, Ackermann-Liebrich U, Gerbase MW, Probst-Hensch NM, Svanes C, Omenaas ER, Neukirch F, Wjst M, Morabia A, Jarvis D, Leynaert B, Zemp E (2009) Is age at menopause increasing across Europe? Results on age at menopause and determinants from two population-based studies. Menopause 16:385-394. https://doi.org/10.1097/gme. 0b013e31818aefef

10. Dumont AS, Crowley RW, Monteith SJ, Ilodigwe D, Kassell NF, Mayer S, Ruefenacht D, Weidauer S, Pasqualin A, Macdonald RL (2010) Endovascular treatment or neurosurgical clipping of ruptured intracranial aneurysms: effect on angiographic vasospasm, delayed ischemic neurological deficit, cerebral infarction, and clinical outcome. Stroke 41:2519-2524. https://doi.org/10.1161/ strokeaha.110.579383

11. Fisher CM, Kistler JP, Davis JM (1980) Relation of cerebral vasospasm to subarachnoid hemorrhage visualized by computerized tomographic scanning. Neurosurgery 6:1-9

12. Foreman B (2016) The pathophysiology of delayed cerebral ischemia. J Clin Neurophysiol 33:174-182. https://doi.org/10.1097/wnp. 0000000000000273

13. Frontera JA, Fernandez A, Schmidt JM, Claassen J, Wartenberg KE, Badjatia N, Connolly ES, Mayer SA (2009) Defining vasospasm after subarachnoid hemorrhage: what is the most clinically relevant definition? Stroke 40:1963-1968. https://doi.org/10.1161/ strokeaha.108.544700

14. Germans MR, Jaja BNR, de Oliviera Manoel AL, Cohen AH, Macdonald RL (2017) Sex differences in delayed cerebral ischemia after subarachnoid hemorrhage. J Neurosurg:1-7. https://doi.org/ 10.3171/2017.3.jns 162808

15. Gross BA, Rosalind Lai PM, Frerichs KU, Du R (2014) Treatment modality and vasospasm after aneurysmal subarachnoid hemorrhage. World Neurosurg 82:e725-e730. https://doi.org/10.1016/j. wneu.2013.08.017
16. Hirashima Y, Kurimoto M, Hori E, Origasa H, Endo S (2005) Lower incidence of symptomatic vasospasm after subarachnoid hemorrhage owing to ruptured vertebrobasilar aneurysms. Neurosurgery 57:1110-1116 discussion 1110-1116

17. Inagawa $T$ (2016) Risk factors for cerebral vasospasm following aneurysmal subarachnoid hemorrhage: a review of the literature. World neurosurgery 85:56-76. https://doi.org/10.1016/j.wneu. 2015.08.052

18. Jabbarli R, Glasker S, Weber J, Taschner C, Olschewski M, Van Velthoven V (2013) Predictors of severity of cerebral vasospasm caused by aneurysmal subarachnoid hemorrhage. J Stroke Cerebrovasc Dis 22:1332-1339. https://doi.org/10.1016/j. jstrokecerebrovasdis.2013.01.006

19. Jamous MA, Nagahiro S, Kitazato KT, Satomi J, Satoh K (2005) Role of estrogen deficiency in the formation and progression of cerebral aneurysms. Part I: experimental study of the effect of oophorectomy in rats. J Neurosurg 103:1046-1051. https://doi.org/10. 3171/jns.2005.103.6.1046

20. Jiang C, Zuo F, Wang Y, Lu H, Yang Q, Wang J (2016) Progesterone changes VEGF and BDNF expression and promotes neurogenesis after ischemic stroke. Mol Neurobiol. https://doi.org/ 10.1007/s12035-015-9651-y

21. Jiang C, Zuo F, Wang Y, Wan J, Yang Z, Lu H, Chen W, Zang W, Yang Q, Wang J (2016) Progesterone exerts neuroprotective effects and improves long-term neurologic outcome after intracerebral hemorrhage in middle-aged mice. Neurobiol Aging 42:13-24. https://doi.org/10.1016/j.neurobiolaging.2016.02.029

22. Kongable GL, Lanzino G, Germanson TP, Truskowski LL, Alves WM, Torner JC, Kassell NF (1996) Gender-related differences in aneurysmal subarachnoid hemorrhage. J Neurosurg 84:43-48. https://doi.org/10.3171/jns.1996.84.1.0043

23. Lawton MT, Vates GE (2017) Subarachnoid hemorrhage. N Engl J Med 377:257-266. https://doi.org/10.1056/NEJMcp 1605827

24. Lin CL, Dumont AS, Wu SC, Wang CJ, Howng SL, Huang YF, Wong WY, Kassell NF, Jeng AY, Kwan AL (2006) 17beta-estradiol inhibits endothelin-1 production and attenuates cerebral vasospasm after experimental subarachnoid hemorrhage. Exp Biol Med 231: 1054-1057

25. Lin CL, Shih HC, Dumont AS, Kassell NF, Lieu AS, Su YF, Hwong SL, Hsu C (2006) The effect of 17beta-estradiol in attenuating experimental subarachnoid hemorrhage-induced cerebral vasospasm. J Neurosurg 104:298-304. https://doi.org/10.3171/jns. 2006.104.2.298

26. Macdonald RL, Wallace MC, Coyne TJ (1994) The effect of surgery on the severity of vasospasm. J Neurosurg 80:433-439. https:// doi.org/10.3171/jns.1994.80.3.0433

27. Macdonald RL, Rosengart A, Huo D, Karrison T (2003) Factors associated with the development of vasospasm after planned surgical treatment of aneurysmal subarachnoid hemorrhage. J Neurosurg 99:644-652. https://doi.org/10.3171/jns.2003.99.4.0644

28. Magge SN, Chen HI, Ramakrishna R, Cen L, Chen Z, Elliott JP, Winn HR, Le Roux PD (2010) Association of a younger age with an increased risk of angiographic and symptomatic vasospasms following subarachnoid hemorrhage. J Neurosurg 112:12081215. https://doi.org/10.3171/2009.9.jns081670

29. McGirt MJ, Mavropoulos JC, McGirt LY, Alexander MJ, Friedman AH, Laskowitz DT, Lynch JR (2003) Leukocytosis as an independent risk factor for cerebral vasospasm following aneurysmal subarachnoid hemorrhage. J Neurosurg 98:1222-1226. https://doi.org/ 10.3171/jns.2003.98.6.1222

30. McGirt MJ, Blessing R, Alexander MJ, Nimjee SM, Woodworth GF, Friedman AH, Graffagnino C, Laskowitz DT, Lynch JR (2006) Risk of cerebral vasopasm after subarachnoid hemorrhage reduced by statin therapy: a multivariate analysis of an institutional experience. J Neurosurg 105:671-674. https://doi.org/10.3171/jns.2006. 105.5.671 
31. Meyer JS, Terayama Y, Takashima S (1993) Cerebral circulation in the elderly. Cerebrovasc Brain Metab Rev 5:122-146

32. Moss EL, Taneja S, Munir F, Kent C, Robinson L, Potdar N, Sarhanis P, McDermott H (2016) Iatrogenic menopause after treatment for cervical cancer. Clin Oncol (R Coll Radiol) 28:766-775. https://doi.org/10.1016/j.clon.2016.08.016

33. Nabulsi AA, Folsom AR, White A, Patsch W, Heiss G, Wu KK, Szklo M (1993) Association of hormone-replacement therapy with various cardiovascular risk factors in postmenopausal women. The Atherosclerosis Risk in Communities Study Investigators. N Engl J Med 328:1069-1075. https://doi.org/10.1056/ nejm199304153281501

34. Parazzini F (2007) Determinants of age at menopause in women attending menopause clinics in Italy. Maturitas 56:280-287. https:// doi.org/10.1016/j.maturitas.2006.09.003

35. Phipps AI, Ichikawa L, Bowles EJ, Carney PA, Kerlikowske K, Miglioretti DL, Buist DS (2010) Defining menopausal status in epidemiologic studies: a comparison of multiple approaches and their effects on breast cancer rates. Maturitas 67:60-66. https:// doi.org/10.1016/j.maturitas.2010.04.015

36. Qureshi AI, Malik AA, Saeed O, Defillo A, Sherr GT, Suri MF (2016) Hormone replacement therapy and the risk of subarachnoid hemorrhage in postmenopausal women. J Neurosurg 124:45-50. https://doi.org/10.3171/2014.12.jns142329

37. Rabb CH, Tang G, Chin LS, Giannotta SL (1994) A statistical analysis of factors related to symptomatic cerebral vasospasm. Acta Neurochir 127:27-31

38. Rosenlrn J, Eskesen V, Schmidt K (1993) Clinical features and outcome in females and males with ruptured intracranial saccular aneurysms. Br J Neurosurg 7:287-290

39. Ryttlefors M, Enblad P, Ronne-Engstrom E, Persson L, Ilodigwe D, Macdonald RL (2010) Patient age and vasospasm after subarachnoid hemorrhage. Neurosurgery 67:911-917. https://doi.org/10. 1227/NEU.0b013e3181ed11ab

40. Schumacher M, Sitruk-Ware R, De Nicola AF (2008) Progesterone and progestins: neuroprotection and myelin repair. Curr Opin Pharmacol 8:740-746. https://doi.org/10.1016/j.coph.2008.10.002

41. Shih HC, Lin CL, Lee TY, Lee WS, Hsu C (2006) 17beta-estradiol inhibits subarachnoid hemorrhage-induced inducible nitric oxide synthase gene expression by interfering with the nuclear factor kappa B transactivation. Stroke 37:3025-3031. https://doi.org/10.1161/ 01.STR.0000249008.18669.5a

42. Sobrino A, Mata M, Laguna-Fernandez A, Novella S, Oviedo PJ, Garcia-Perez MA, Tarin JJ, Cano A, Hermenegildo C (2009) Estradiol stimulates vasodilatory and metabolic pathways in cultured human endothelial cells. PLoS One 4:e8242. https://doi.org/ 10.1371/journal.pone.0008242

43. Stepaniak U, Szafraniec K, Kubinova R, Malyutina S, Peasey A, Pikhart H, Pajak A, Bobak M (2013) Age at natural menopause in three central and eastern European urban populations: the HAPIEE study. Maturitas 75:87-93. https://doi.org/10.1016/j.maturitas. 2013.02.008
44. Tabuchi S (2015) Relationship between postmenopausal estrogen deficiency and aneurysmal subarachnoid hemorrhage. Behav Neurol 2015:720141. https://doi.org/10.1155/2015/720141

45. Tada Y, Makino H, Furukawa H, Shimada K, Wada K, Liang EI, Murakami S, Kudo M, Kung DK, Hasan DM, Kitazato KT, Nagahiro S, Lawton MT, Hashimoto T (2014) Roles of estrogen in the formation of intracranial aneurysms in ovariectomized female mice. Neurosurgery 75:690-695; discussion 695. https://doi.org/ 10.1227/neu.0000000000000528

46. Tada Y, Wada K, Shimada K, Makino H, Liang EI, Murakami S, Kudo M, Shikata F, Pena Silva RA, Kitazato KT, Hasan DM, Kanematsu Y, Nagahiro S, Hashimoto T (2014) Estrogen protects against intracranial aneurysm rupture in ovariectomized mice. Hypertension 63:1339-1344. https://doi.org/10.1161/ hypertensionaha. 114.03300

47. Teasdale GM, Drake CG, Hunt W, Kassell N, Sano K, Pertuiset B, De Villiers JC (1988) A universal subarachnoid hemorrhage scale: report of a committee of the World Federation of Neurosurgical Societies. J Neurol Neurosurg Psychiatry 51:1457

48. Teunissen LL, Rinkel GJ, Algra A, van Gijn J (1996) Risk factors for subarachnoid hemorrhage: a systematic review. Stroke 27:544 549

49. van Swieten JC, Koudstaal PJ, Visser MC, Schouten HJ, van Gijn J (1988) Interobserver agreement for the assessment of handicap in stroke patients. Stroke 19:604-607

50. Vergouwen MD, Vermeulen M, van Gijn J, Rinkel GJ, Wijdicks EF, Muizelaar JP, Mendelow AD, Juvela S, Yonas H, Terbrugge KG, Macdonald RL, Diringer MN, Broderick JP, Dreier JP, Roos YB (2010) Definition of delayed cerebral ischemia after aneurysmal subarachnoid hemorrhage as an outcome event in clinical trials and observational studies: proposal of a multidisciplinary research group. Stroke 41:2391-2395. https://doi.org/10.1161/strokeaha. 110.589275

51. Yousef K, Crago E, Kuo CW, Horowitz M, Hravnak M (2010) Predictors of delayed cerebral ischemia after aneurysmal subarachnoid hemorrhage: a cardiac focus. Neurocrit Care 13:366-372. https://doi.org/10.1007/s12028-010-9408-4

\section{Comments}

A large retrospective study evaluating the effect of sex and age on the prediction, and occurrence of symptomatic vasospasm, and clinical outcome. The novel finding is that female age 55-75 are at higher risks of symptomatic vasospasm and poor outcome, possibly due to postmenopausal hormonal effect, lack of estrogen and decrease in NO production thus decreasing the vasodilator effect on blood vessels. There are many speculation based on a retrospective study with several limitations as outlined by the authors. If they could regroup the hormonal data on this subgroup of patients, it could significantly enhance the value of this study. Perhaps for the future analyses.

Amir Dehdashti

NY, USA 


\section{Acknowledgements}

I would like to thank heartfully my wife Sandra Ghozzi, my parents Bebia Bouhnek and Abdelkrim Chihi, my brother Anis Chihi and my best friend Riadh Fehri for their unconditional support and encouragements through the entire process of writing my thesis.

Also, I would like to thank my friend Dr. med. Oliver Gembruch for his thoughtful advice, kind support and helpfulness through the entire period of writing, article publication and thesis defense; and thank "mon meilleur ami" Thiemo Dinger for his moral support and presence on the day of my thesis defense.

Furthermore, I would like to thank PD. Dr. med. Ramazan Jabbarli for the idea and initiation of the first article and his motivational support and generous supervision in the entire process of writing and publishing the paper.

Moreover, I am very grateful to my doctoral supervisor PD. Dr. med. Karsten Henning Wrede for the careful revision of this work as well as his kind support and advice throughout the entire administrative process without which this cumulative doctoral thesis would not come true.

Last but not least, I would like to thank PD. Dr. med. Marvin Darkwah Oppong for giving me the chance to work with him in the second article and be one of his co-authors. 
Aus datenschutzrechlichen Gründen ist der Lebenslauf in der elektronischen Dissertation nicht enthalten 
